\title{
High Salt Intake Recruits Tonic Activation of NR2D Subunit- Containing Extrasynaptic NMDARs in Vasopressin Neurons
}

\author{
${ }^{\circledR}$ Chiranjivi Neupane, ${ }^{1,2}$ Ramesh Sharma, ${ }^{1,2}$ Yoon Hyung Pai, ${ }^{1}$ So Yeong Lee, ${ }^{3}$ Byeong Hwa Jeon, ${ }^{1,2}$ \\ Hyun-Woo Kim, ${ }^{1,2}$ Javier E. Stern, ${ }^{4}$ and Jin Bong Park ${ }^{1,2}$ \\ ${ }^{1}$ Department of Physiology, Chungnam National University, Daejeon 35015, Republic of Korea, ${ }^{2}$ Biomedicine, Brain Research Institute, College of \\ Medicine, Chungnam National University, Daejeon 35015, Republic of Korea, ${ }^{3}$ Laboratory of Veterinary Pharmacology, College of Veterinary \\ Medicine and Research Institute for Veterinary Science, Seoul National University, Seoul 151-742, Republic of Korea, and ${ }^{4}$ Neuroscience Institute, \\ Georgia State University, Atlanta, Georgia 30302
}

In addition to producing a classical excitatory postsynaptic current via activation of synaptic NMDA receptors (NMDARs), glutamate in the brain also induces a tonic NMDAR current $\left(I_{\text {NMDA }}\right)$ via activation of extrasynaptic NMDARs (eNMDARs). However, since $\mathrm{Mg}^{2+}$ blocks NMDARs in nondepolarized neurons, the potential contribution of eNMDARs to the overall neuronal excitatory/inhibitory (E/I) balance remains unknown. Here, we demonstrate that chronic (7 d) salt loading (SL) recruited NR2D subunitcontaining NMDARs to generate an $\mathrm{Mg}^{2+}$-resistant tonic $I_{\mathrm{NMDA}}$ in nondepolarized [ $V_{\mathrm{h}}$ (holding potential) $-70 \mathrm{mV}$ ] vasopressin (VP; but not oxytocin) supraoptic nucleus (SON) neurons in male rodents. Conversely, in euhydrated (EU) and 3 d SL mice, $\mathrm{Mg}^{2+}$-resistant tonic $I_{\mathrm{NMDA}}$ was not observed. Pharmacological and genetic intervention of $\mathrm{NR} 2 \mathrm{D}$ subunits blocked the $\mathrm{Mg}^{2+}$ resistant tonic $I_{\mathrm{NMDA}}$ in VP neurons under SL conditions, while an NR2B antagonist unveiled $\mathrm{Mg}^{2+}$-sensitive tonic $I_{\mathrm{NMDA}}$ but not $\mathrm{Mg}^{2+}$-resistant tonic $I_{\mathrm{NMDA}}$. In the EU group VP neurons, an $\mathrm{Mg}^{2+}$-resistant tonic $I_{\mathrm{NMDA}}$ was not generated by increased ambient glutamate or treatment with coagonists (e.g., D-serine and glycine). Chronic SL significantly increased NR2D expression but not NR2B expression in the SON relative to the EU group or after $3 \mathrm{~d}$ under SL conditions. Finally, $\mathrm{Mg}^{2+}$-resistant tonic $I_{\mathrm{NMDA}}$ selectively upregulated neuronal excitability in VP neurons under SL conditions, independent of ionotropic GABAergic input. Our results indicate that the activation of NR2D-containing NMDARs constitutes a novel mechanism that generates an $\mathrm{Mg}^{2+}$-resistant tonic $I_{\mathrm{NMDA}}$ in nondepolarized VP neurons, thus causing an E/I balance shift in VP neurons to compensate for the hormonal demands imposed by a chronic osmotic challenge.

Key words: iMK801; NR2D; oxytocin; salt loading; tonic NMDA; vasopressin

\section{Significance Statement}

The hypothalamic supraoptic nucleus (SON) consists of two different types of magnocellular neurosecretory cells (MNCs) that synthesize and release the following two peptide hormones: vasopressin (VP), which is necessary for regulation of fluid homeostasis; and oxytocin (OT), which plays a major role in lactation and parturition. NMDA receptors (NMDARs) play important roles in shaping neuronal firing patterns and hormone release from the SON MNCs in response to various physiological challenges. Our results show that prolonged $(7 \mathrm{~d})$ salt loading generated a $\mathrm{Mg}^{2+}$-resistant tonic NMDA current mediated by NR2D subunit-containing receptors, which efficiently activated nondepolarized VP (but not OT) neurons. Our findings support the hypothesis that NR2D subunit-containing NMDARs play an important adaptive role in adult brain in response to a sustained osmotic challenge.

Received July 6, 2020; revised Nov. 19, 2020; accepted Nov. 25, 2020.

Author contributions: C.N., R.S., Y.H.P., S.Y.L., B.H.J., H.-W.K., J.E.S., and J.B.P. designed research; C.N.,

R.S., and Y.H.P. performed research; C.N., R.S., and J.B.P. analyzed data; J.E.S. and J.B.P. wrote the paper.

Y.H. Pai's present address: Hallym University Sacred Heart Hospital, 22, Gwanpyeong-ro 170 beon-gil,

Dongan-gu, Anyang-si, Gyeonggi-do 14068, Republic of Korea.

The authors declare no competing financial interests.

This work was supported by the National Research Foundation of Korea (Grant 2015R1D1A1A02059430), the Korean Health Technology R\&D project through the Korean Health Industry Development Institute (Grant HI18C0660), and the National Institute of Neurological Disorders and Stroke/National Institutes of Health (Grant R01-NS-094640 (to J.E.S.).

Correspondence should be addressed to Jin Bong Park at jinbong@cnu.ac.kr.

https://doi.org/10.1523/JNEUROSCI.1742-20.2020

Copyright $\odot 2021$ the authors

\section{Introduction}

NMDA receptors (NMDARs) are a subclass of glutamate-gated ion channels that can mediate the majority of excitatory input on neurons in the brain. At synaptic and extrasynaptic sites, NMDARs are thought to be responsible for maintaining an excitatory/inhibitory balance in two distinct modalities. Synaptic NMDARs mediate the classical transient EPSCs, whereas extrasynaptic NMDARs (eNMDARs) generate a persistent, tonic NMDAR current $\left(I_{\text {NMDA}}\right.$; Papouin and Oliet, 2014). NMDARs can be distinguished from other ionotropic glutamate receptors because of characteristics such as high $\mathrm{Ca}^{2+}$ permeability and a 
strong voltage-dependent channel block caused by external $\mathrm{Mg}^{2+}$ (Traynelis et al., 2010). This $\mathrm{Mg}^{2+}$ channel block inhibits ion flux through agonist-bound open NMDARs at resting membrane potential $\left(V_{\mathrm{m}}\right)$ values, thus requiring the coincident agonists and membrane depolarization to relieve the $\mathrm{Mg}^{2+}$ channel block and allow ions to flow through the channel. Consequently, eNMDARs generate tonic $I_{\mathrm{NMDA}}$ at low concentrations of extracellular $\mathrm{Mg}^{2+}$ and/or with a depolarized membrane potential (Le Meur et al., 2007; Fleming et al., 2011; Hanson et al., 2019). However, to mediate tonic $I_{\mathrm{NMDA}}$ with the low levels of extracellular glutamate normally found in the brain, novel strategies are required, targeting eNMDARs to reduce or completely relieve the $\mathrm{Mg}^{2+}$ channel block at resting membrane potentials. The mechanisms underlying this phenomenon are yet to be fully understood.

Most NMDARs are tetrameric assemblies of two NR1 subunits and up to four different NR2 (NR2A, NR2B, NR2C, and NR2D) subunits (Paoletti et al., 2013; Wyllie et al., 2013; Hansen et al., 2018). The identity of the four different NR2 subunits determines the properties of the receptor. For example, NR2D-containing NMDARs are located exclusively extrasynaptically (Lozovaya et al., 2004). NR2D subunits confer a high agonist affinity (Erreger et al., 2007), a weak desensitization (Krupp et al., 1998; Villarroel et al., 1998), and a slow deactivation (Vicini et al., 1998; Wyllie et al., 1998) of NMDARs. Of note, NR2D receptors are less sensitive to $\mathrm{Mg}^{2+}$ block (Monyer et al., 1994; Kuner and Schoepfer, 1996; Momiyama et al., 1996; Huang and Gibb, 2014) and less $\mathrm{Ca}^{2+}$ permeable (Siegler Retchless et al., 2012) compared with NR2A and NR2B receptors. Therefore, NR2D-containing receptors may be ideal candidates for sensing low ambient glutamate concentrations in the extrasynaptic space and for generating tonic $I_{\mathrm{NMDA}}$ with less excitotoxicity in the brain. To date, the contribution of NR2D-containing NMDARs to tonic $I_{\mathrm{NMDA}}$ in nondepolarized neurons has not been investigated in the mature brain, partly because expression of the NR2D subunit is developmentally and regionally regulated. The NR2D subunit is widely expressed during late embryonic and early postnatal development; subsequently, it is generally preserved at low levels in a few regions of the adult brain (Watanabe et al., 1992; Monyer et al., 1994; Dunah et al., 1996; Wenzel et al., 1996; Liu and Wong-Riley, 2010). For example, among the four NR2 subunit mRNAs expressed (Al-Ghoul et al., 1997; Decavel and Curras, 1997), NR2B and NR2D are commonly expressed in the supraoptic nucleus (SON; Doherty and Sladek, 2011). However, the functional significance of NR2D expression in the mature brain remains unknown.

The SON consists of two different types of magnocellular neurosecretory cells (MNCs) that contribute to the hypothalamo-neurohypophyseal system (Swanson and Sawchenko, 1983). SON MNCs synthesize and release vasopressin (VP), a peptide hormone necessary for the regulation of fluid homeostasis, and oxytocin (OT), a closely related hormone that stimulates lactation and parturition. Salt intake increases both plasma sodium and osmolality. Therefore, VP neurons respond to increased osmolality by increasing neuronal activity and hormone release from the neurohypophysis during salt loading (SL). Here, we show that prolonged SL recruits NR2Dcontaining NMDARs to generate $\mathrm{Mg}^{2+}$-resistant tonic $I_{\mathrm{NMDA}}$ in nondepolarized VP neurons. This leads to selective upregulation of the neuronal excitability of VP over OT neurons under SL conditions and contributes to fluid homeostasis via hormone secretion.

\section{Materials and Methods}

Animal experiments. All animal experimentation was approved by the Chungnam National University Institutional Animal Care and Use Committee (Registration \#2025-1-21) and was conducted in accordance with the National Institutes of Health Guide for the Care and Use of Laboratory Animals. Male wild-type (WT) or NR2D knock-out (KO) C57BL/6N mice weighing 20-24 g, and Sprague Dawley (SD) rats and double-transgenic Wistar rats weighing 120-180 g, which express both the arginine VP (AVP)-enhanced green fluorescent protein (AVP-eGFP) fusion gene (Ueta et al., 2005) and the OT-monomeric red fluorescent protein 1 (OT-mRFP1) fusion gene (Katoh et al., 2011) were randomly assigned to either the euhydrated (EU) control group or SL group. NR2D KO C57BL/6N mice (Ikeda et al., 1995) were provided by the RIKEN BioResource Research Center (no. RBRC01840) through the National BioResource Project of the Ministry of Education, Culture, Sports, Science and Technology, Japan. All animals had access to food ad libitum throughout the experiments. The SL groups had their water replaced with $2 \% \mathrm{NaCl}$ to drink for 3 or $7 \mathrm{~d}$. At the end of the SL protocol, the animals were anesthetized with avertin $(250 \mathrm{mg} / \mathrm{kg}$, i.p.; Millipore Sigma) and decapitated to extract the brain. Blood was collected from each animal after decapitation and was centrifuged for serum collection. Serum osmolality was measured using the freezing point depression method and a micro-osmometer (model 210, Fiske Associates).

Seven days of SL resulted in increased serum osmolality in both WT SD (EU group: $307 \pm 0.6 \mathrm{mOsm} / \mathrm{kg}, n=6$; vs SL group: $367.8 \pm 4.4$ $\mathrm{mOsm} / \mathrm{kg}, n=7$ ) and transgenic Wistar rats (EU group: $308.1 \pm 0.7$ $\mathrm{mOsm} / \mathrm{kg}, n=31$; vs SL group: $360.8 \pm 7.0 \mathrm{mOsm} / \mathrm{kg}, n=43)$. In C57BL/6 WT mice, serum osmolality increased to $349.3 \pm 1.3 \mathrm{mOsm} / \mathrm{kg}$ $(n=14)$ and $382.2 \pm 5.5 \mathrm{mOsm} / \mathrm{kg}(n=21)$ in the 3 and $7 \mathrm{~d}$ SL groups, respectively, and to $327.3 \pm 0.7 \mathrm{mOsm} / \mathrm{kg}(n=17)$ in the EU group. Seven days of SL also significantly increased serum osmolality in NR2D $\mathrm{KO}$ mice (EU group: $326.9 \pm 1.8 \mathrm{mOsm} / \mathrm{kg}, n=10$; vs SL group: $383.5 \pm 7.6 \mathrm{mOsm} / \mathrm{kg}, n=12$ ).

Electrophysiology and data analysis. Patch-clamp recordings from SON MNCs were obtained from hypothalamic slices $(300 \mu \mathrm{m})$ as previously described (Park et al., 2007). Briefly, the rats and mice were anesthetized with avertin and decapitated, and the brains were rapidly isolated. Slices were maintained in, and perfused with, artificial CSF (aCSF) containing $126 \mathrm{~mm} \mathrm{NaCl}, 5 \mathrm{~mm} \mathrm{KCl}, 1.2 \mathrm{~mm} \mathrm{MgCl}_{2}, 26 \mathrm{~mm}$ $\mathrm{NaHCO}_{3}, 1.2 \mathrm{~mm} \mathrm{NaH}_{2} \mathrm{PO}_{4}, 10 \mathrm{~mm}$ glucose, and $2.4 \mathrm{~mm} \mathrm{CaCl}_{2}$ at $\mathrm{pH}$ 7.3-7.4 and saturated with $95 \% \mathrm{O}_{2}$ and $5 \% \mathrm{CO}_{2}$. In a subset of voltageclamp recordings, low $\mathrm{Mg}^{2+}$ aCSF $\left(20 \mu \mathrm{MgCl}_{2}\right)$ was used to facilitate measurements of NMDA-mediated currents. The internal solution contained $130 \mathrm{~mm}$ K-gluconate, $10 \mathrm{~mm} \mathrm{KCl,} 10 \mathrm{~mm}$ HEPES, $5 \mathrm{~mm}$ $\mathrm{Mg}^{2+}$ ATP, $0.9 \mathrm{~mm} \mathrm{MgCl}_{2}$, and $10 \mathrm{~mm}$ EGTA. Recordings were obtained at $35^{\circ} \mathrm{C}$, using a Multiclamp $700 \mathrm{~B}$ (Molecular Devices). Currents were filtered at $1 \mathrm{kHz}$ and digitized at $10 \mathrm{kHz}$ (Digidata 1440A and pClamp 9 software, Molecular Devices). Input-output (I-O) curves were plotted as previously described (Pandit et al., 2015). Briefly, the number of evoked spikes versus injected current in response to depolarizing step pulses (of $10 \mathrm{pA}$ from 0 to $60 \mathrm{pA}, 1.2 \mathrm{~s}$ duration) were plotted, and fitted by a Boltzmann function: $y=1 /\left\{1+\exp \left[\left(I_{\mathrm{h}}-I_{50}\right) / k\right]\right\}$, in which $y$ is the number of spikes at a given injected current [hyperpolarization-activated cation current $\left.\left(I_{\mathrm{h}}\right)\right], I_{50}$ the current at which half of the maximal spikes are evoked, and $k$ is the slope factor. Data were excluded if the series resistance was not stable throughout the entire recording ( $20 \%$ change) or if neuronal input resistance (IR) was $<550 \mathrm{M} \Omega$ at the beginning of the recording.

The NMDA receptor-mediated tonic current (tonic $I_{\mathrm{NMDA}}$ ) was defined as changes in the holding current $\left(I_{\text {holding }}\right)$ in the presence of ionotropic GABA receptor antagonist picrotoxin $(200 \mu \mathrm{M})$ and was calculated by the difference in $I_{\text {holding }}$ measured as the average of a $2 \mathrm{~min}$ steady-state baseline segment obtained before and after the application of NMDAR antagonists. $I_{\mathrm{NMDA}}$ was recorded and calculated at $-70 \mathrm{mV}$ unless otherwise stated. The effects of $I_{\mathrm{NMDA}}$ on firing discharge were studied using a current-clamp method. Firing rates (spontaneous or evoked using DC current injection) were recorded in continuous mode and calculated using Mini Analysis Program (Synaptosoft; RRID:SCR_002184) for a 
period of $\sim 3 \mathrm{~min}$ before and after application of the NMDAR antagonist (Park et al., 2006).

Drugs were added to the aCSF perfusing solution at differing concentrations. The final concentration of dimethylsulfoxide was $<0.05 \%$, when used as a vehicle. DL-2-amino-5-phospho-nopentanoic acid, $(2 S *, 3 \mathrm{R} *)$-1-(phenanthren-2-carbonyl) piperazine-2, 3-dicarboxylic acid (PPDA) and DL-threo- $\beta$-benzyloxyaspartic acid (TBOA) were all purchased from Tocris Bioscience. All other drugs were purchased from Sigma-Aldrich.

Single-cell RT-PCR. Single-cell RT-PCR was performed following patch-clamp recordings to categorize the VP neurons, as previously described with minor modifications (Lee et al., 2012). The cytoplasm of the neuron that showed $\mathrm{Mg}^{2+}$-sensitive $I_{\mathrm{NMDA}}$ was pulled into a patch pipette with negative pressure and under visual control to ensure the nucleus was not contained. The cytoplasm in the pipette was dissipated into a prepared microtube containing $5 \mu \mathrm{l}$ of nuclease-free water (Qiagen) and then immediately stored at $-70^{\circ} \mathrm{C}$. Single-cell cDNA samples were synthesized using an Applied Biosystems High Capacity cDNA Reverse Transcription Kit (Thermo Fisher Scientific) according to the manufacturer instructions. PCR amplification was then performed using singlecell cDNA as a template. PCR mixtures contained $1 \mu \mathrm{l}$ of both forward and reverse $10 \mu \mathrm{M}$ primers, $10 \mu \mathrm{l}$ of $2 \times$ Taq master mix buffer (GoTaq Green Master Mix, Promega), and 2-4 $\mu \mathrm{l}$ of cDNA template. The annealing temperature in the thermal cycler was $60^{\circ} \mathrm{C}$, and, in total, 50 cycles were performed. Primers targeting VP (5'-CCTCACCTCTGCCTGCTACTT- $3^{\prime}$ and $5^{\prime}$-GGGGGCGATGGCTCAGTAGAC-3') were synthesized by Bioneer. Final PCR products were visualized by electrophoresis using $1.8 \%$ agarose gels stained with ethidium bromide. All PCR products were purified using a PCR purification kit (Qiagen), and the purified products were then sequenced to confirm amplification of the correct sequences. Genomic DNA samples not treated with reverse transcriptase were used as negative controls to assess for contamination of samples.

Western blotting. SON sections were lysed with $1 \times$ passive lysis buffer (Cell Signaling Technology) and quantified using a Coomassie Protein Assay Kit (Bio-Rad). Approximately $50 \mu \mathrm{g}$ of protein was loaded onto a $10 \%$ SDS polyacrylamide gel for electrophoresis and then transferred onto nitrocellulose membranes. The blots were then blocked with TBST $(0.1 \%$ Tween 20 in $1 \times$ Tris-buffered saline) containing $5 \%$ skimmed milk for $1 \mathrm{~h}$ at room temperature. The blots were then incubated at $4^{\circ} \mathrm{C}$ overnight with primary antibodies against the NMDAR NR2B subunit (1:1000; catalog \#06-600, Millipore; RRID:AB_310193) and NR2D subunit (1:1000; catalog \#AGC-020, Alomone Labs; RRID: AB_10658334) diluted in TBST containing 5\% skim milk. Next the blots were incubated with a horseradish peroxidase-conjugated goat anti-rabbit (catalog \#7074, Cell Signaling Technology; RRID:AB_2099233) and anti-mouse (catalog \#31430, Thermo Fisher Scientific; RRID:AB_ 228307) secondary antibody (1:1000). A Pierce enhanced chemiluminescence detection kit (Thermo Fisher Scientific) was used to visualize antibody binding, and the intensity of the bands was measured using ImageJ software 1.42q (National Institutes of Health).

Statistical analysis and experimental design. Numerical data are presented as the mean \pm SEM. To assess the differences in tonic $I_{\mathrm{NMDA}}$ under SL conditions, a hierarchical testing procedure was performed. In the first step, a Shapiro-Wilk test was used to test the null hypothesis that the data distribution was normal with a significance level of $5 \%$. For data with a normal distribution, the statistical significance of comparisons was assessed using either a two-sample $t$ test or a one-way ANOVA followed by a post hoc test (e.g., Bonferroni's test). If the null hypothesis was rejected, nonparametric tests were used with Microcal Origin software (RRID:SCR_002815). For all experiments male mice or rats were used. Tonic $I_{\text {NMDA }}$ was categorized into two modalities, either the $\mathrm{Mg}^{2+}$-sensitive tonic $I_{\mathrm{NMDA}}$ measured by $I_{\text {holding }}$ shift was induced by increasing the extracellular $\mathrm{Mg}^{2+}$ concentration from $20 \mu \mathrm{M}$ to $1.2 \mathrm{mM}$ at $V_{\mathrm{h}}$, at $-70 \mathrm{mV}$, or the $\mathrm{Mg}^{2+}$-resistant tonic $I_{\mathrm{NMDA}}$ was measured by $I_{\text {holding }}$ shift induced by NMDAR antagonists at $V_{\mathrm{h}}$, at $-70 \mathrm{mV}$ using normal aCSF. Electrophysiological recordings were taken from three or more animals per group, and three to four slices were collected per animal. The Mann-Whitney test was used to compare two groups if the data were not normally distributed. The pharmacological sensitivity of tonic $I_{\mathrm{NMDA}}$ to various NMDAR antagonists was investigated using both WT and NR2D KO animals. To compare $I_{\text {NMDA }}$ amplitude and protein expression (NR2B and NR2D) in the EU group, the $3 \mathrm{~d}$ SL group and the $7 \mathrm{~d}$ SL group, a one-way ANOVA followed by a post hoc test was used. The effects of $\mathrm{Mg}^{2+}$-resistant tonic $I_{\mathrm{NMDA}}$ on neuronal firing were investigated using NR2C/NR2D antagonists and compared using a Wilcoxon signed-rank test. Finally, the effects of $\mathrm{Mg}^{2+}$-resistant tonic $I_{\mathrm{NMDA}}$ on the input-output function of VP neurons in the EU and SL groups were compared using a two-way repeated-measures (RM) ANOVA followed by a post hoc test.

\section{Results}

To assess the functional significance of tonic NMDAR activation in SON MNCs during an osmotic insult, we compared the tonic $I_{\mathrm{NMDA}}$, defined as the shift in $I_{\text {holding }}$ after the application of an NMDAR antagonist in the EU and SL animals. The total tonic $I_{\mathrm{NMDA}}$, composed of $\mathrm{Mg}^{2+}$-sensitive and $\mathrm{Mg}^{2+}$-resistant tonic $I_{\mathrm{NMDA}}$, was measured by increasing the extracellular $\mathrm{Mg}^{2+}$ concentration $\left(\left[\mathrm{Mg}^{2+}\right]_{\mathrm{o}}\right)$ from $20 \mu \mathrm{M}$ to $1.2 \mathrm{~mm}$ followed by treatment with different NMDAR antagonists.

\section{SL generated an $\mathrm{Mg}^{2+}$-resistant tonic $I_{\mathrm{NMDA}}$ in nondepolarized VP neurons}

First, we compared tonic $I_{\mathrm{NMDA}}$ in SD rats in the EU, $3 \mathrm{~d}$ SL, and

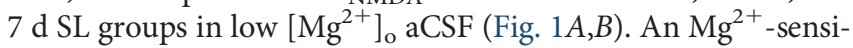
tive tonic $I_{\mathrm{NMDA}}$ (indicated by an outward shift in $I_{\text {holding }}$ after an increase in $\left[\mathrm{Mg}^{2+}\right]_{\mathrm{o}}$ ) was observed in all tested neurons, confirming previous findings that tonic persistent activation of NMDARs mediates tonic $I_{\mathrm{NMDA}}$ in SON MNCs (Fleming et al., 2011). $\mathrm{Mg}^{2+}$-sensitive tonic $I_{\mathrm{NMDA}}$ did not differ among the EU $(10.0 \pm 0.6 \mathrm{pA} ; n=18), 3 \mathrm{~d}$ SL $(9.5 \pm 1.6 \mathrm{pA} ; n=11)$, and $7 \mathrm{~d}$ SL groups $\left(8.5 \pm 0.8 \mathrm{pA} ; n=21\right.$; one-way ANOVA, $F_{(2,47)}=1.75$, $p=0.184)$. Application of AP5 $(100 \mu \mathrm{M})$ in the presence of 1.2 $\mathrm{mm}\left[\mathrm{Mg}^{2+}\right]_{\mathrm{o}}$ further shifted the $I_{\text {holding outwardly (a phenom- }}$ enon defined as an $\mathrm{Mg}^{2+}$-resistant tonic $I_{\mathrm{NMDA}}$ ) in 12 of $21 \mathrm{SON}$ MNCs isolated from seven rats from the $7 \mathrm{~d}$ SL group (Fig. $1 A$, $B)$. In contrast, AP5 caused minimal changes in $I_{\text {holding }}$ in all SON slices obtained from rats in the EU and $3 \mathrm{~d}$ SL groups $(0.3 \pm 0.2$ vs $0.2 \pm 0.4 \mathrm{pA}$, respectively). Although $7 \mathrm{~d}$ SL generated $\mathrm{Mg}^{2+}$-resistant tonic $I_{\mathrm{NMDA}}$, total tonic $I_{\mathrm{NMDA}}$ values were not different among the three groups.

The SON consists of VP and OT neurons (Swanson and Sawchenko, 1983); therefore, our results showing that $7 \mathrm{~d}$ of SL generated an $\mathrm{Mg}^{2+}$-resistant $I_{\mathrm{NMDA}}$ in a subgroup of SON MNCs may imply that an osmotic insult leads to the recruitment of $\mathrm{Mg}^{2+}$-resistant tonic $I_{\mathrm{NMDA}}$ in a cell type-specific manner. To investigate this hypothesis, experiments were repeated in AVPeGFP and OT-mRFP1 neurons (Fig. $1 C-E$ ). Here, we compared the effect of AP5 on $I_{\text {holding }}$ at a holding potential (i.e., $V_{\mathrm{h}}$ ) of $-70 \mathrm{mV}$ in normal aCSF. In the EU group, all tested VP neurons (11 neurons from four rats) and OT neurons (10 neurons from four rats) failed to express an $\mathrm{Mg}^{2+}$-resistant tonic $I_{\mathrm{NMDA}}$ (Fig. $1 D, E)$. Conversely, AP5 selectively produced an $\mathrm{Mg}^{2+}$-resistant tonic $I_{\mathrm{NMDA}}$ in 11 of $12 \mathrm{VP}$ neurons in the SL groups but this did not occur in OT neurons (four rats in each group; Fig. $1 D, E)$. This result implies that SL recruits an $\mathrm{Mg}^{2+}$-resistant tonic $I_{\mathrm{NMDA}}$ in a VP neuron-specific manner. In both the EU and SL groups, application of the ionotropic glutamate receptor antagonist, kynurenic acid (KynA; $5 \mathrm{~mm}$ ) in addition to AP5 (AP5 + KynA) completely blocked PSCs but failed to cause a further significant change in $I_{\text {holding }}$ (Fig. 1C). This finding supports the dominant role of NMDARs in the 
generation of tonic glutamate currents under our recording conditions.

In a subset of experiments, we investigate the sensitivity of $I_{\mathrm{NMDA}}$ to intracellular MK-801, which has been used to selectively inhibit NMDARs in single cells (Berretta and Jones, 1996). Intracellular MK-801 (1 mM) contained in a recording pipette significantly reduced both total $I_{\text {NMDA }}$ (and/or $\mathrm{Mg}^{2+}$-sensitive $I_{\text {NMDA }}$ ) in the EU MNCs (from 12.2 \pm 1.3 to $12.2 \pm 1.3 \mathrm{pA}$ ) and $7 \mathrm{~d}$ SL MNCs (from $20.6 \pm 1.7$ to $10.0 \pm 1.6 \mathrm{pA}, n=6-7$ in each, $p<0.01$ in both cases). Combined with the fact that intracellular MK-801 partially but selectively inhibits NMDAR current (Sun et al., 2018), these results suggested that $I_{\mathrm{NMDA}}$ reflects the blockade of NMDARs in SON MNCs being recorded in our recording conditions.

Next, we combined post hoc single-cell RT-PCR with electrophysiology in WT SD rats. The results are summarized in Figure $1 F$. An $\mathrm{Mg}^{2+}$-resistant $I_{\mathrm{NMDA}}$ was prominent in 10 different identified VP neurons but was absent in 7 of the non-VP neurons, further supporting the conclusion that the SL-induced $\mathrm{Mg}^{2+}$-resistant $I_{\mathrm{NMDA}}$ in VP neurons is not related to the genetic modification of AVP-eGFP neurons.

\section{PPDA blocked $\mathrm{Mg}^{2+}$-resistant tonic $I_{\text {NMDA }}$ in nondepolarized SL-VP neurons}

To investigate the molecular composition of NMDARs generating an $\mathrm{Mg}^{2+}$-resistant $I_{\mathrm{NMDA}}$, we assessed the pharmacological properties of the $\mathrm{Mg}^{2+}$-resistant $I_{\mathrm{NMDA}}$ in $\mathrm{VP}$ neurons in the EU and SL groups (Fig. 2).

First, we directly compared the $I_{\text {holding }}$ shift in SL VP neurons produced by sequential application of an NR2C/NR2Dselective NMDAR antagonist, PPDA (Feng et al., 2004). PPDA (1 $\mu \mathrm{M})$ outwardly shifted the $I_{\text {holding }}$ of nondepolarized VP neurons from the SL groups in normal aCSF and subsequent addition of 100 $\mu \mathrm{M}$ AP5 (PPDA + AP5) failed to induce a further shift in $I_{\text {holding }}$ (Fig. $2 A, B$ ). In contrast, ifenprodil (IFD; $10 \mu \mathrm{M}$ ), a selective antagonist of the NR2B subunit (Chenard and Menniti, 1999) failed to alter $I_{\text {holding }}$ in VP neurons from the SL groups (Fig. $2 B$ ).

To investigate whether eNMDARs mediate $\mathrm{Mg}^{2+}$-resistant tonic $I_{\mathrm{NMDA}}$, we examined and compared the effect of memantine, an NMDAR antagonist that preferentially targets extrasynaptic receptors (Xia et al., 2010; Wu and Johnson, 2015) and MK-801, a use-dependent NMDAR open channel antagonist (Huettner and Bean, 1988), on $I_{\text {holding }}$ in nondepolarized VP neurons in the SL groups. The addition of memantine $(1 \mu \mathrm{M})$ resulted in $\mathrm{Mg}^{2+}$-resistant $I_{\mathrm{NMDA}}$ comparable to that of PPDA, and subsequent addition of AP5 (memantine + AP5) did not
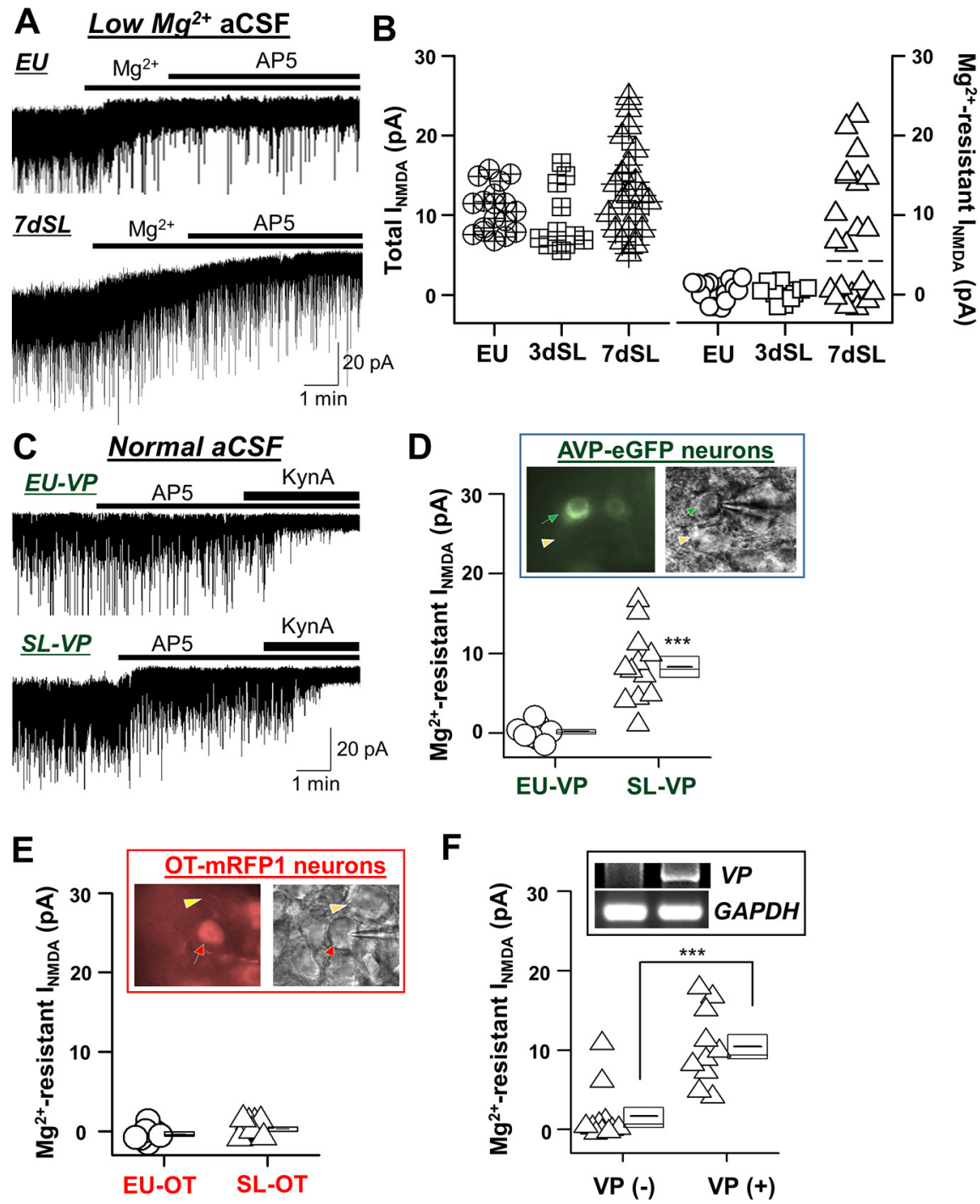

Figure 1. Cell type-specific changes in tonic $/_{\text {NMDA }}$ in nondepolarized SON MNCs from rats in the euhydrated and salt-loading groups. $A$, Representative traces of neurons from the euhydrated and $7 \mathrm{~d}$ salt-loaded (7dSL) groups showing the outward shift in / holding induced by increased $\left[\mathrm{Mg}^{2+}\right]_{0}$ (from $20 \mu \mathrm{m}$ to $1.2 \mathrm{~mm}$ ) followed by the addition of AP5 (100 $\mu \mathrm{m}$ ). B, Total $I_{\text {NMDA }}\left(I_{\text {holding }}\right.$ shift induced by $\left[\mathrm{Mg}^{2+}\right]_{0}$ increase and the addition of AP5) are summarized for the EU, $3 \mathrm{~d}$ salt-loaded (3dSL) and 7dSL groups (left). $\mathrm{Mg}^{2+}$-resistant $I_{\mathrm{NMDA}}$ (/ holding shift induced by AP5 in the presence of $1.2 \mathrm{~mm}\left[\mathrm{Mg}^{2+}\right]_{0}$ ) values are summarized in the right panel. Note that $\mathrm{Mg}^{2+}$-resistant $I_{\mathrm{NMDA}}$ was observed in neurons in the 7dSL group but not in the EU and 3dSL groups. $C$, Representative traces showing $\mathrm{Mg}^{2+}$-resistant $I_{\text {NMDA }}$ in AVP-eGFP neurons in one representative rat from the EU (EU-VP and SL (SL-VP) groups. D, Summarized amplitudes of $\mathrm{Mg}^{2+}$-resistant $I_{\text {NMDA }}$ in the labeled neurons under the EU and SL conditions ( $* * * p<0.001$ compared with EU, two-sample $t$ test). Representative images of AVP-eGFP (arrow) and non-VP (arrowhead) neurons from the recording shown in the inset. $\boldsymbol{E}$, Summarized amplitudes of $\mathrm{Mg}^{2+}$-resistant $I_{\text {NMDA }}$ in labeled OT neurons under the EU and SL conditions. Representative images of OT-mRFP1 neurons (arrow) and non-0T neu-

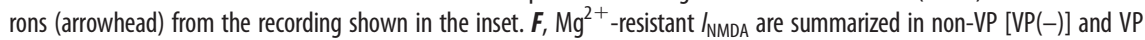
neurons $[V P(+)]$ assessed by post hoc single-cell RT-PCR. A representative PCR result in two groups is shown in the inset; $* * * p<0.001$ compared with EU, two-sample $t$ test.

further alter $I_{\text {holding }}$ (Fig. $\left.2 A, B\right)$. In contrast, MK-801 (40 $\left.\mu \mathrm{M}\right)$ failed to produce any effect on the $I_{\text {holding }}$ of VP neurons in the SL groups (Fig. 2B).

In summary, the amplitudes of $\mathrm{Mg}^{2+}$-resistant $I_{\mathrm{NMDA}}$ produced by memantine, PPDA, and AP5 did not differ significantly in VP neurons in the SL groups (Fig. $2 B$ ), implying that $\mathrm{Mg}^{2+}$ resistant $I_{\mathrm{NMDA}}$ is predominantly mediated by extrasynaptic NR2C/NR2D-containing receptors. All NMDAR antagonists (PPDA, memantine, MK-801, and ifenprodil) caused minimal changes to $I_{\text {holding }}$ in nondepolarized VP neurons in the EU group (data not shown), supporting the conclusion that SL 
A
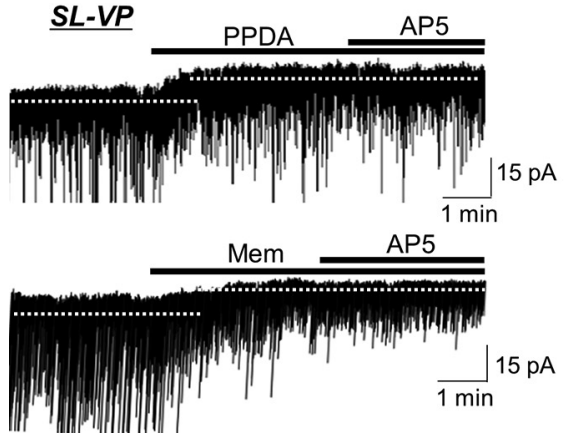

B

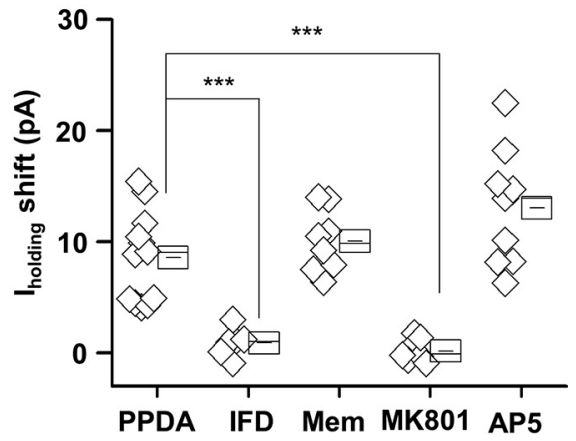

Figure 2. Pharmacological properties of tonic $I_{\text {NMDA }}$ in nondepolarized VP neurons. $\boldsymbol{A}$, Representative traces of VP neurons from rats in the SL group showing the outward shift in / holding induced by PPDA (1 $\mu \mathrm{m}$, top) and memantine (Mem; $1 \mu \mathrm{m}$, bottom) in normal aCSF with a nondepolarized membrane potential $\left(V_{h},-70 \mathrm{mV}\right)$. Note that additional application of AP5 $(100 \mu \mathrm{m})$ did not cause further changes in $I_{\text {holding }}$ in the same neurons. The dotted lines indicate the mean $I_{\text {holding }}$ under each condition. $\boldsymbol{B}$, Mean changes in / holding induced by the addition of PPDA, ifenprodil (IFD, $10 \mu \mathrm{m})$, Mem, MK801 (40 $\mu \mathrm{m})$, and AP5 in VP neurons from the SL group, one-way ANOVA $\left(F_{(4,39)}=16.4, p<0.001\right.$, with Bonferroni post hoc test, $* * * p<0.001$, compared with PPDA).
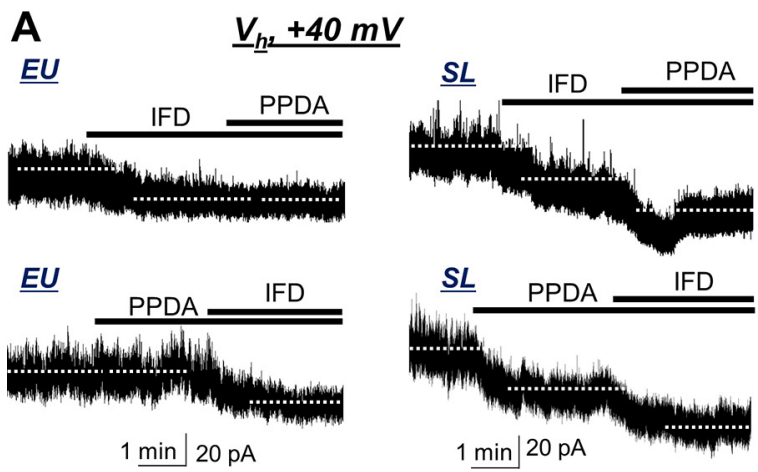

B

Figure 3. Pharmacological properties of tonic $I_{\text {NMDA }}$ in depolarized VP neurons. $A$, Representative traces showing the Iholding changes induced by the sequential addition of $10 \mu \mathrm{m} \mathrm{IFD} \mathrm{and} 1 \mu \mathrm{M}$ PPDA (IFD + PPDA; top and bottom, respectively) in neurons from the $E U$ and $S L$ groups with a depolarized membrane potential $\left(V_{\mathrm{h}^{\prime}}+40 \mathrm{mV}\right)$. The dotted lines indicate the mean $I_{\text {holding }}$ under each condition. $\boldsymbol{B}$, Summarized $I_{\text {holding }}$ changes induced by IFD and PPDA in VP neurons from both the EU and SL groups ( $n=9 /$ group). $* * p=0.003$ compared with EU, Mann-Whitney test.

recruits additional NR2C/NR2D-containing receptors to mediate $\mathrm{Mg}^{2+}$-resistant $I_{\mathrm{NMDA}}$ of VP neurons.

\section{NR2B antagonist ifenprodil blocked tonic $I_{\mathrm{NMDA}}$ in depolarized VP neurons}

To verify the contribution of NR2B-containing NMDARs to tonic $\mathrm{I}_{\mathrm{NMDA}}$ in SON MNCs, we investigated the effects of ifenprodil on $I_{\text {holding }}$ in VP neurons in the EU and SL groups at a depolarized membrane potential.

In accordance with a previous report (Fleming et al., 2011), ifenprodil (IFD) efficiently produced tonic $I_{\mathrm{NMDA}}$ under depolarized conditions in normal aCSF (Fig. 3). At a $V_{\mathrm{h}}$ of $+40 \mathrm{mV}$, $10 \mu \mathrm{M}$ IFD induced a significant and similar inward $I_{\text {holding }}$ shift in VP neurons in both the EU and SL groups, and subsequent addition of $1 \mu \mathrm{M}$ 1PPDA (IFD + PPDA) produced a further inward shift in $I_{\text {holding }}$ VP neurons in the SL groups, but not in the EU group (Fig. 3A,B).

A similar result was observed with sequential application of PPDA and IFD (Fig. 3A), implying that an $\mathrm{Mg}^{2+}$ channel block is essential for both inward and outward tonic currents mediated by NR2B-containing NMDARs, whereas NR2C/NR2D-containing NMDARs contributed to the generation of tonic $I_{\mathrm{NMDA}}$ in nondepolarized VP neurons in the SL groups.

Increased EPSC frequency with hyperosmotic solution failed to recruit $\mathrm{Mg}^{2+}$-resistant tonic $I_{\mathrm{NMDA}}$ in VP neurons

Hypertonic stimuli excite primary osmosensory neurons in the organum vasculosum lamina terminalis (OVLT; Sayer et al., 1984; Honda et al., 1990; Ciura and Bourque, 2006), sending target-selective excitatory inputs to VP neurons (Yang et al., 1994; Stachniak et al., 2014). Glutamate released from presynaptic terminals has the ability to diffuse and activate eNMDARs on neighboring cells (Asztely et al., 1997). Therefore, this enhanced glutamatergic input could recruit $\mathrm{Mg}^{2+}$-resistant tonic $I_{\mathrm{NMDA}}$ in VP neurons after hyperosmotic stimulation. To assess this possibility, we examined whether acute hyperosmotic stimulation in brain slices (with the addition of $50 \mathrm{~mm}$ mannitol to aCSF) generated an $\mathrm{Mg}^{2+}$-resistant tonic $I_{\text {NMDA }}$ in VP neurons.

Direct application of the hyperosmotic solution ( $50 \mathrm{~mm}$ mannitol to aCSF) did not cause any significant change in the $I_{\text {holding }}$ of VP neurons in the EU group (Fig. $4 A, B$ ), although it significantly increased the frequency of EPSCs (Fig. $4 C, D)$ but with no significant changes in amplitude or decay time kinetics, (Fig. $4 E, F)$, in accordance with a previous report (Yokoyama et al., 2010). Similar results were observed in hypothalamic slices that were incubated in hyperosmotic solution for 20-30 min. Addition of AP5 $(100 \mu \mathrm{M})$ did not cause any significant $I_{\text {holding }}$ changes in VP neurons in the EU group, even after incubation in hyperosmotic solution. These results disprove the notion that increased ambient glutamate with enhanced glutamatergic input from OVLT generates $\mathrm{Mg}^{2+}$-resistant tonic $I_{\mathrm{NMDA}}$ in VP neurons.

Increased glutamate concentration was not sufficient to generate $\mathbf{M g}^{2+}$-resistant tonic $I_{\mathrm{NMDA}}$ in VP neurons

In addition to spillover of glutamate from the synaptic cleft, altered glutamate transporter (GluT) activity could lead to the accumulation of glutamate in the extracellular space, activating eNMDARs and therefore enhancing tonic $I_{\mathrm{NMDA}}$ strength (Fleming et al., 2011). To test this hypothesis, we investigated the effects of PPDA on $I_{\text {holding }}$ in the presence of $30 \mu \mathrm{M}$ glutamate or TBOA in VP neurons in both the EU and SL groups (Fig. 5).

In the presence of TBOA $(100 \mu \mathrm{M})$, a broad-spectrum GluT antagonist (Shimamoto et al., 1998), PPDA (1 $\mu \mathrm{M})$ caused a significant change in $I_{\text {holding }}$ in VP neurons in the SL groups but not in the EU group (Fig. 5A,B); however, subsequent addition of $5 \mathrm{~mm}$ KynA (PPDA + KynA) caused a significant outward shift in $I_{\text {holding }}$ in all groups. Similar results were observed in the presence of $30 \mu \mathrm{m}$ glutamate (Fig. $5 C$ ). PPDA failed to produce any significant change in $I_{\text {holding }}$ in VP neurons in the EU group while in the presence of glutamate. However, it did produce tonic $I_{\mathrm{NMDA}}$ in the SL groups, implying that an increase in ambient glutamate levels is not enough to generate $\mathrm{Mg}^{2+}$. 
resistant $I_{\mathrm{NMDA}}$ in SON MNCs. The PPDAinduced $I_{\text {holding }}$ shift of VP neurons in the SL groups did not differ in the absence $(8.5 \pm 1.1 \mathrm{pA}$; Fig. 2$)$ or presence of glutamate or TBOA (one-way ANOVA, $F_{(2,25)}=$ $0.42, p=0.66)$, implying that $\mathrm{Mg}^{2+}$-resistant tonic $I_{\mathrm{NMDA}}$ became saturated in VP neurons in the SL groups.

These results support the hypothesis that the $\mathrm{Mg}^{2+}$-resistant $I_{\mathrm{NMDA}}$ of VP neurons in the SL groups cannot be attributed simply to increased ambient glutamate levels in the SON.

Increased coagonist concentration was not sufficient to generate $\mathrm{Mg}^{2+}$ resistant tonic $I_{\mathrm{NMDA}}$ in VP neurons NMDARs are unique among glutamate receptors in their requirement for the binding of coagonists, such as glycine or $\mathrm{D}$-serine, in addition to glutamate. In SON MNCs, D-serine is the dominant coagonist at synapses, while glycine is more potent at extrasynaptic receptors (Papouin et al., 2012). We next explored whether the application of exogenous coagonists (glycine or D-serine) generated $\mathrm{Mg}^{2+}$-resistant $I_{\mathrm{NMDA}}$ in VP neurons in the EU or SL groups. Glycine $(3 \mu \mathrm{M})$ or Dserine $(100 \mu \mathrm{M})$ failed to produce any changes in $I_{\text {holding }}$ in VP neurons in the EU or SL groups $(p=0.991$ and $0.493, n=4-5$ in all groups, two-sample $t$ test). These results agree with those of previous studies and imply that the glycine binding sites of the eNMDARs mediating tonic $I_{\mathrm{NMDA}}$ become saturated in the brain (Le Meur et al., 2007; Papouin et al., 2012).

The NR2C/D subunit-selective potentiator CIQ failed to recruit $\mathrm{Mg}^{2+}$-resistant tonic $I_{\mathrm{NMDA}}$ in VP neurons in the EU and SL groups

Next, we used an NR2C/NR2D subunit-selective potentiator, CIQ (Mullasseril et al., 2010), to investigate its effect on $\mathrm{Mg}^{2+}$-resistant tonic $I_{\mathrm{NMDA}}$ in VP neurons. CIQ $(20 \mu \mathrm{M})$ failed to produce any effect on $I_{\text {holding }}$ in VP neurons in the EU and SL groups ( $p=0.687, n=6$ in both groups; two-sample $t$ test), supporting the hypothesis that the SL-induced, NR2D-mediated $\mathrm{Mg}^{2+}$-resistant tonic $I_{\mathrm{NMDA}}$ in VP neurons is maximally activated under these particular recording conditions.

\section{NR2D KO prevented SL-induced $\mathrm{Mg}^{2+}$-resistant tonic $I_{\mathrm{NMDA}}$} in SON MNCs

To confirm the role of NR2D-containing NMDARs in SLinduced $\mathrm{Mg}^{2+}$-resistant tonic $I_{\mathrm{NMDA}}$, we compared the $\mathrm{Mg}^{2+}$-resistant tonic $I_{\mathrm{NMDA}}$ of C57BL/6 WT mice and of NR2D KO mice under both the EU and SL conditions.

First, we compared tonic $I_{\mathrm{NMDA}}$ in EU and SL WT mice (Fig. $6 A-D)$ to examine whether SL-induced $\mathrm{Mg}^{2+}$-resistant tonic $I_{\text {NMDA }}$ is species specific. The $\mathrm{Mg}^{2+}$-sensitive tonic $I_{\text {NMDA }}$ was observed in all tested neurons, and no significant differences were observed in the EU or 3 and $7 \mathrm{~d}$ SL groups (Fig. $6 A, B$ ). The paired-sample $t$ test.

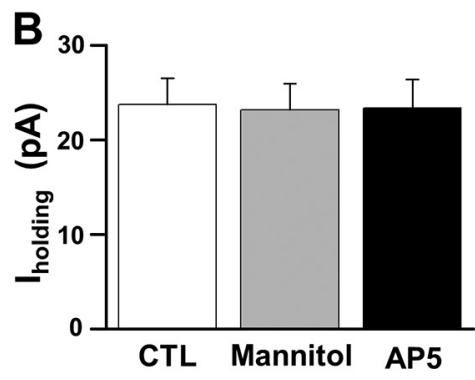

a. CTL

b. Mannitol
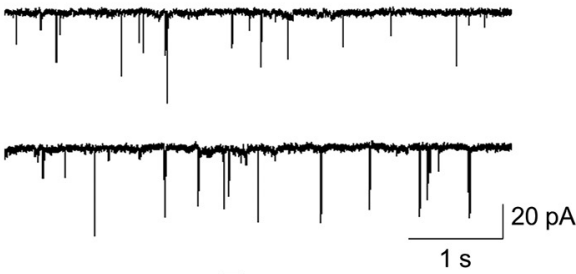

$E$

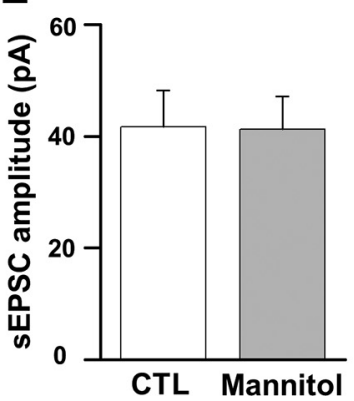

$F$

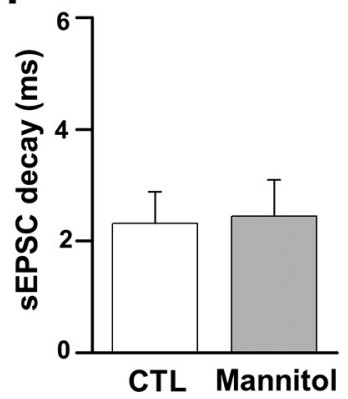

Figure 4. Acute hyperosmotic stimulus failed to generate $\mathrm{Mg}^{2+}$-resistant $/_{\text {NMDA }}$ in VP neurons. $A$, A representative example showing the lack of change in $I_{\text {holding }}$ after a hyperosmotic stimulus containing $50 \mathrm{~mm}$ mannitol $(360 \mathrm{~m} 0 \mathrm{sm} / \mathrm{kg})$ and the addition of AP5 (100 $\mu \mathrm{M})$ and KynA (5 mM). $\boldsymbol{B}$, Mean / holding under the three different conditions, as in $\boldsymbol{A}$, are summarized in synaptic glutamatergic activity, as in $A, D-F$ Mean changes in the spontaneous EPSC frequency $(D)$, the degree of ongoing time kinetics $(\boldsymbol{F})$ induced by a hyperosmotic solution ( $n=6 /$ condition). (TL, Control. $* p=0.03$, compared with control,

addition of AP5 $(100 \mu \mathrm{M})$ in the presence of normal $\left[\mathrm{Mg}^{2+}\right]_{\mathrm{o}}$ resulted in an $\mathrm{Mg}^{2+}$-resistant tonic $I_{\mathrm{NMDA}}$ in 10 of $20 \mathrm{SON}$ MNCs tested in the $7 \mathrm{~d}$ SL group, whereas minimal changes were observed in the SON MNCs of the EU and $3 \mathrm{~d}$ SL groups (Fig. $6 A, C)$. Despite these findings, the total $I_{\mathrm{NMDA}}$ did not significantly differ among the three groups (Fig. 6D).

Next, we compared $\mathrm{Mg}^{2+}$-resistant tonic $I_{\mathrm{NMDA}}$ between WT and NR2D KO mice under EU and $7 \mathrm{~d}$ SL conditions (Fig. 6E,F). PPDA $(1 \mu \mathrm{M})$ produced an $\mathrm{Mg}^{2+}$-resistant $I_{\mathrm{NMDA}}$ in 11 of 20 SON MNCs from seven different mice in the SL group, but no significant changes in $I_{\text {holding }}$ were observed in 10 neurons tested in the EU group from four different WT mice (Fig. 6E,F). In contrast, PPDA in combination with AP5 (PPDA + AP5) caused only minimal changes in $I_{\text {holding }}$ of all tested SON MNCs from NR2D KO mice in both the EU group (six neurons from three mice) and SL groups (14 neurons from five mice; Fig. 6E,F), implying that NR2D-containing NMDARs play an essential role in mediating SL-induced $\mathrm{Mg}^{2+}$-resistant tonic $I_{\mathrm{NMDA}}$ in SON MNCs.

Chronic SL selectively increased NR2D expression over NR2B subunit expression in the SON

To investigate whether SL induces $\mathrm{Mg}^{2+}$-resistant tonic $I_{\mathrm{NMDA}}$ via altered expression of extrasynaptic NMDARs in the SON, we 
A
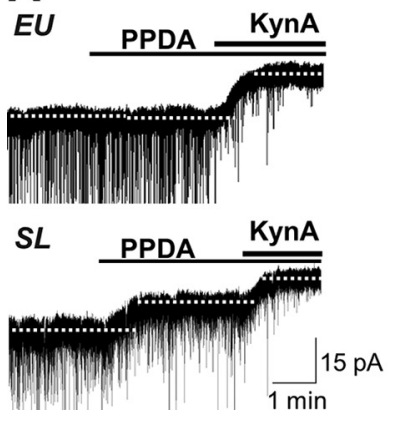

Figure 5. Increased extracellular glutamate failed to generate $\mathrm{Mg}^{2+}$-resistant $I_{\text {NMDA }}$ of VP neurons. $\boldsymbol{A}$, Representative examples of the effects of PPDA $(1 \mu \mathrm{m})$ and $\mathrm{KynA}(5 \mathrm{mM})$ on $/_{\text {holding }}$ in the presence of $100 \mu \mathrm{m}$ TBOA, a glutamate transporter antagonist. PPDA produced tonic $I_{\text {NMDA }}$ in the SL groups but not in the EU group. $B$, PPDA-induced $I_{\text {holding }}$ changes $\left(I_{\text {PPDA }}\right)$ in the presence of TBOA, as shown in the bar graph $(n=8 ; * * * p<0.001$, compared with EU, two-sample $t$ test). $C$, IPPDA in the presence of $30 \mu \mathrm{m}$ glutamate as shown in the bar graph $(n=8 ; * * * p<0.001$, compared with EU, two-sample $t$ test).
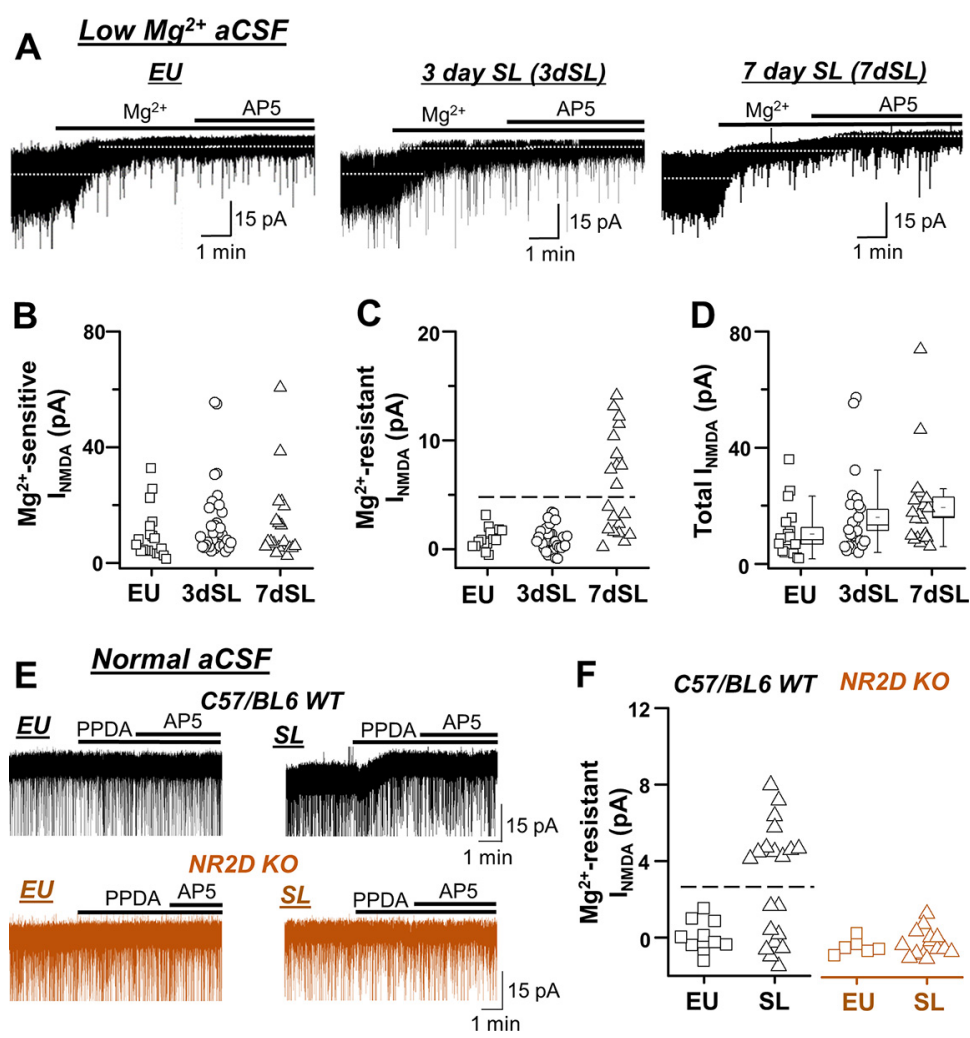

Figure 6. NR2D KO prevented the generation of SL-induced $\mathrm{Mg}^{2+}$-resistant $I_{\mathrm{NMDA}} \cdot \boldsymbol{A}$, Representative traces showing that increased $\left[\mathrm{Mg}^{2+}\right]_{0}$ (from $20 \mu \mathrm{M}$ to $1.2 \mathrm{~mm}$ ) and the addition of AP5 (100 $\left.\mu \mathrm{m}\right)$ caused an outward shift in $I_{\text {holding }}$ in SON MNCs in C57BL/6 mice. AP5 induced an / holding shift in the $7 \mathrm{~d} \mathrm{SL} \mathrm{(7dSL)} \mathrm{group} \mathrm{but} \mathrm{not} \mathrm{in} \mathrm{the} \mathrm{euhy-}$ drated or $3 \mathrm{~d} S \mathrm{SL}(3 \mathrm{dSL})$ groups. The dotted lines indicate mean I $I_{\text {holding }}$ level under each condition. $\boldsymbol{B}, \boldsymbol{C}, I_{\text {holding }}$ changes induced by sequential application of $\mathrm{Mg}^{2+}\left(\mathrm{Mg}^{2+}\right.$-sensitive $\left.I_{\text {NMDA }} ; B\right)$ and AP5 $\left(\mathrm{Mg}^{2+}\right.$-resistant $I_{\text {NMDA }}$; C) in each neuron type are plotted. $\boldsymbol{D}$, Summarized total $I_{\text {NMDA }}$ in the three groups. $\boldsymbol{E}$, Representative current traces showing the effect of PPDA $(1 \mu \mathrm{m})$ on $I_{\text {holding }}$ in SON MNCS in normal aCSF in the four different groups. Note that SL induced $\mathrm{Mg}^{2+}$-resistant $I_{\text {NMDA }}$ in the wild-type mice but not in the NR2D KO mice. $\boldsymbol{F}$, Amplitudes of $\mathrm{Mg}^{2+}$-resistant $I_{\text {NMDA }}$ measured by PPDA are shown for the four different groups.

compared the expression of NMDAR subunits NR2B and NR2D in the SON of the EU group with that of mice in the 3 and $7 \mathrm{~d}$ SL groups. In all three groups, Western blot analysis showed the presence of NR2B and NR2D in the SON (Fig. 7A). Importantly, while NR2D subunit polypeptide expression was significantly higher in the $7 \mathrm{~d}$ SL mice than in the EU and $3 \mathrm{~d}$ SL groups (Fig. 7C), NR2B expression was similar in all three groups (Fig. $7 B$ ).
Blockage of $\mathrm{Mg}^{2+}$-resistant tonic $I_{\mathrm{NMDA}}$ downregulated the neuronal firing of SL-VP neurons

To determine the contribution of $\mathrm{Mg}^{2+}$. resistant tonic $I_{\mathrm{NMDA}}$ to resting $V_{\mathrm{m}}$ and IR in SON MNCs, recordings were obtained using the current-clamp mode. We investigated the association between $I_{\mathrm{NMDA}}$ attenuation and increased IR in VP neurons in the SL groups using PPDA, which selectively blocks $\mathrm{Mg}^{2+}$-resistant tonic $I_{\text {NMDA }}$ (Table 1).

A two-way RM ANOVA revealed that IR was dependent on the addition of $1 \mu \mathrm{M}$ $\operatorname{PPDA}\left(F_{(3,41)}=5.89, p=0.04\right)$, but not on SL $\left(F_{(3,41)}=2.56, p=0.13\right)$. A post hoc test revealed that PPDA significantly increased IR in VP neurons in the SL groups $(p<$ $0.05)$, whereas it caused minimal changes to VP neurons in the EU group ( $p>0.05$; Table 1). Similarly, $V_{\mathrm{m}}$ was dependent on the addition of PPDA $\left(F_{(3,41)}=6.45\right.$, $p=0.02)$, but not on SL $\left(F_{(3,41)}=0.02\right.$, $p=0.82$ ). In accordance with its effect on $I_{\text {holding }}$ (Fig. 2), PPDA caused minimal effects on $V_{\mathrm{m}}$ (from $-58.2 \pm 1.1$ to $-57.7 \pm$ $1.0 \mathrm{mV}, n=11, p>0.05)$ in VP neurons in the EU group, whereas it significantly hyperpolarized $V_{\mathrm{m}}($ from $-56.5 \pm 1.1$ to $-59.0 \pm$ $1.0 \mathrm{mV}, n=11, p<0.05$,) in VP neurons in the SL groups.

To assess further the functional significance of $\mathrm{Mg}^{2+}$-resistant tonic $I_{\mathrm{NMDA}}$ in SL SON MNCs, we examined the effect of PPDA on the spontaneous firing activity of VP and OT neurons (Fig. 8). The spontaneous firing frequency was not dependent on the cell type (two-way ANOVA, $\left.F_{(3,25)}=0.004, p=0.94\right)$. Furthermore, SL had no significant effect on the spontaneous firing frequency of VP (EU group: $3.2 \pm 1.3 \mathrm{~Hz}, n=6$; vs SL group: $5.7 \pm 1.5$ $\mathrm{Hz}, n=11$ ) or OT neurons (EU group: $3.4 \pm 2.2 \mathrm{~Hz}, n=4$; vs SL group: $5.2 \pm 2.1$ $\mathrm{Hz}, n=7$; two-way ANOVA, $F_{(3,25)}=0.93$, $p=0.34)$ or on the proportion of spontaneously active neurons of the VP (6 of 11 neurons in the EU group vs 11 of 13 neurons in the SL group, $p=0.18$, Fisher's exact test) and OT neurons (4 of 7 neurons in the EU group vs 7 of 9 neurons in the SL groups, $p=0.60$, Fisher's exact test). All tested neurons that were silent were then subjected to a current injection to produce a firing frequency of $\sim 2 \mathrm{~Hz}$ to investigate the effect of PPDA on ongoing firing activity (Fig. 8).

In accordance with its effect on $\mathrm{Mg}^{2+}$-resistant tonic $I_{\mathrm{NMDA}}$, PPDA $(1 \mu \mathrm{M})$ significantly decreased the neuronal firing rate in VP neurons in the SL groups $(n=13, p=0.0002$, Wilcoxon signed-rank test), while it caused a minimal decrease in VP neurons in the EU group $(n=11, p=0.311$, Wilcoxon signed-rank test; Fig. $8 A, B$ ). PPDA did not cause any significant changes in the neuronal firing of OT neurons in the EU or SL groups (Fig. 
A

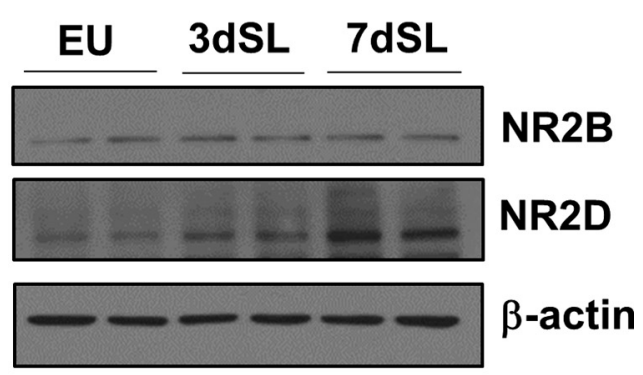

B
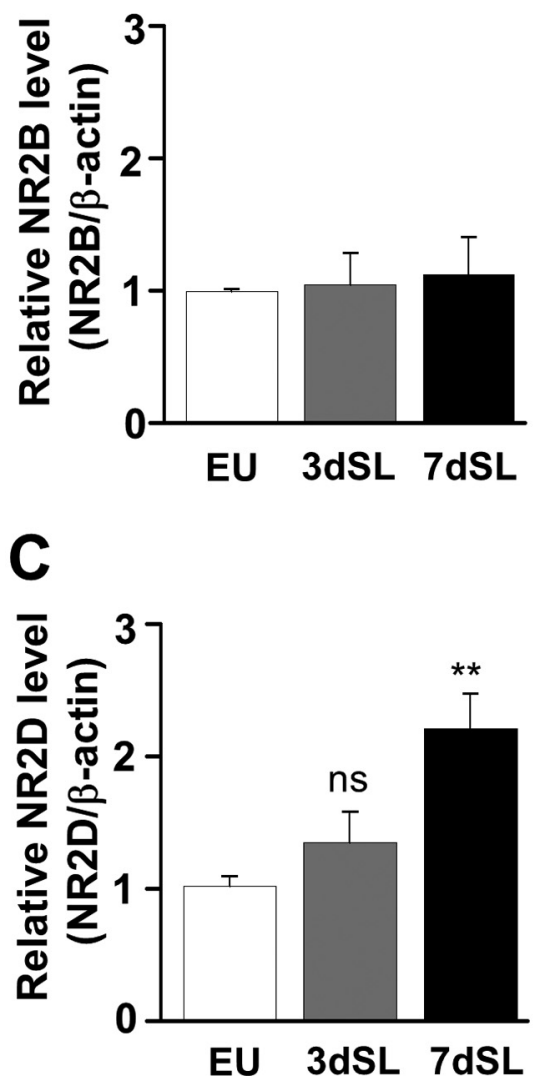

Figure 7. SL increased NR2D expression in the SON. $\boldsymbol{A}$, Representative Western blot analysis showing NMDAR NR2B and NR2D subunit expression under EU and SL conditions. $B, N R 2 B$ and $C$, NR2D subunit expression in the SON in the EU and SL groups is summarized and compared, respectively. The protein expression was normalized to the level detected in the EU group and compared with the expression in SL animals. Summarized data shown are as the mean $\pm \mathrm{SE}$ ( $n=5$ and $n=11$ for NR2B and NR2D subunits, respectively). One-way ANOVA, $F_{(2,30)}=8.48$, $p<0.05$; with Bonferroni post hoc test, $* * p<0.01$.

$8 A, B)$. Combined with the results that PPDA increased the input resistance in VP neurons in the SL groups (Table 1), these results further suggested that altered input resistance by the blockade of $\mathrm{Mg}^{2+}$-resistant tonic $I_{\mathrm{NMDA}}$ could be sufficient to increase the neuronal firing in the neurons.

To determine whether the decrease in SON neuronal firing after blockade of $\mathrm{Mg}^{2+}$-resistant tonic $I_{\mathrm{NMDA}}$ required an intact ionotropic receptor-mediated GABAergic synaptic input, experiments were repeated in the presence of the ionotropic GABA receptor antagonist picrotoxin $(200 \mu \mathrm{M})$. All recorded neurons were spontaneously active in the presence of picrotoxin. The results are summarized in Fig. 8, $C$ and $D$. In the presence of picrotoxin, PPDA significantly decreased the neuronal firing rate in
Table 1. Basic membrane properties of VP SON MNCs

\begin{tabular}{lllll}
\hline & & $n$ & $\mathbb{R}(\mathrm{m} \Omega)$ & $V_{\mathrm{m}}(\mathrm{mV})$ \\
\hline EU & CTL & 11 & $746.1 \pm 40.2$ & $-58.2 \pm 1.1$ \\
& PPDA & 11 & $749.2 \pm 45.2$ & $-57.7 \pm 1.0$ \\
SL & CTL & 11 & $659.4 \pm 29.8$ & $-56.5 \pm 1.1$ \\
& PPDA & 11 & $705.6 \pm 28.4^{*}$ & $-59.0 \pm 1.0^{*}$ \\
\hline CTL, Control. \\
$* p<0.05$ compared with respective CTL, two-way RM ANOVA with Bonferroni post hoc test.
\end{tabular}

VP neurons in the SL groups $(n=8, p=0.02$, paired samples $t$ test) but not in the VP neurons in the EU group. In VP neurons in the SL groups, the effect of PPDA on ongoing firing in the presence of picrotoxin ( $64.2 \pm 9.2 \%$ of control, $n=8)$ was no different from that produced in the absence of picrotoxin (66 \pm $8.1 \%$ of control, $n=13, p=0.82$, two-sample $t$ test).

Together, these results imply that blockade of $\mathrm{Mg}^{2+}$-resistant tonic $I_{\text {NMDA }}$ is sufficient to decrease neuronal excitability and firing discharge of VP neurons under SL conditions, even in the absence of an active GABAergic input.

Blockade of $\mathrm{Mg}^{2+}$-resistant tonic $I_{\mathrm{NMDA}}$ shifted the inputoutput function in VP neurons in the SL groups

To assess the functional significance of $\mathrm{Mg}^{2+}$-resistant tonic $I_{\mathrm{NMDA}}$ on repetitive firing activity, the effect of PPDA on the I-O function in VP neurons was compared between the EU and SL groups. Depolarizing current steps of increasing amplitude were applied and the numbers of resulting spikes were plotted as a function of the depolarizing steps (Fig. 9). At all levels of current injection, the numbers of action potentials elicited in VP neurons did not differ significantly between the EU and SL groups (Fig. $9 A$ ). The I-O function was expressed using the Boltzmann equation with a half-maximal current $\left(I_{50}\right)$ of $31.9 \pm 1.8 \mathrm{pA}$ and a slope factor $(k)$ of $8.7 \pm 0.6 \mathrm{pA}(n=11)$ in VP neurons in the EU group (Fig. $9 B$ ), which were no different from the values for VP neurons in the SL groups $\left(I_{50}=31.5 \pm 1.6 \mathrm{pA}, k=8.4 \pm 0.3 \mathrm{pA}\right.$, $n=11)$. A two-way RM ANOVA revealed that the firing responses were dependent on current injection $\left(F_{(1,140)}=132.80\right.$, $p<0.001)$ but not on SL $\left(F_{(1,140)}=0.05, p=0.94\right)$. PPDA $(1 \mu \mathrm{M})$ significantly decreased the firing response in VP neurons in the SL groups but not in the EU group (Fig. 9A). As a result, PPDA significantly increased the $I_{50}$ in VP neurons in the SL groups to $38.5 \pm 1.6 \mathrm{pA}\left(F_{(3,41)}=18.91\right.$, with Bonferroni post hoc test, $p<0.001$ ), while the changes in the EU group did not show statistical significance $(32.8 \pm 2.1 \mathrm{pA}, n=11, p>0.05)$.

\section{Discussion}

The main findings of this study are that (1) an osmotic challenge mediated by $7 \mathrm{~d}$ (but not $3 \mathrm{~d}$ ) of SL generated an $\mathrm{Mg}^{2+}$-resistant tonic $I_{\mathrm{NMDA}}$ in nondepolarized VP neurons; (2) the $\mathrm{Mg}^{2+}$-resistant tonic $I_{\mathrm{NMDA}}$ in VP neurons in the SL groups was not a result of increased ambient glutamate concentration; (3) pharmacological blockade and genetic deletion of NR2D subunits inhibited the $\mathrm{Mg}^{2+}$-resistant tonic $I_{\mathrm{NMDA}}$ in VP neurons in the SL groups; (4) the $\mathrm{Mg}^{2+}$-resistant tonic $I_{\mathrm{NMDA}}$ selectively regulated the firing activity of VP (but not of OT) neurons in the SL groups; and (5) SL increased NR2D expression in the SON. These findings indicate that increased expression and activation of NR2D-containing NMDARs is a novel mechanism generating an $\mathrm{Mg}^{2+}$. resistant tonic $I_{\mathrm{NMDA}}$ in VP neurons, which may contribute to elevated neuronal activity and, in turn, VP hormone release to aid fluid homeostasis following the chronic osmotic insult. To the best of our knowledge, this is the first evidence that 
A
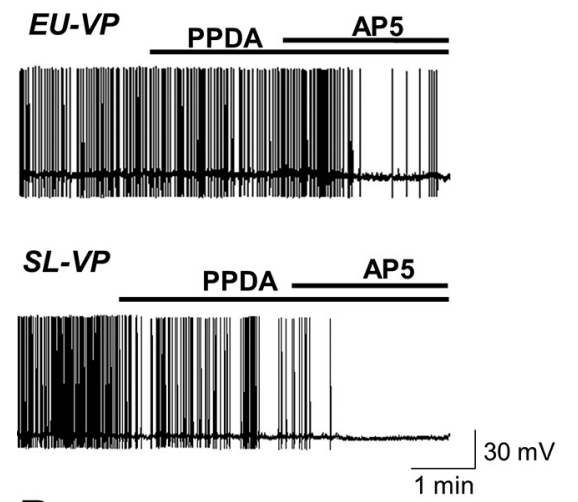

B

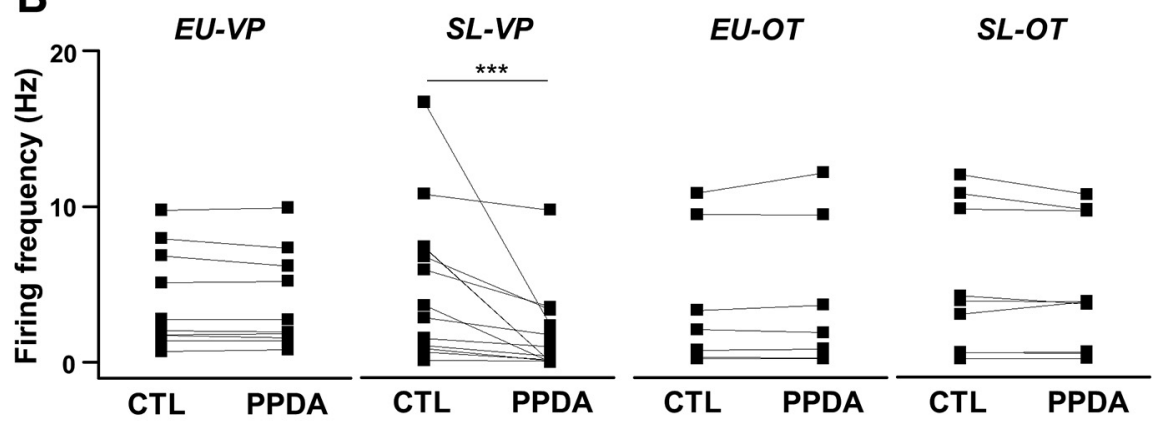

C
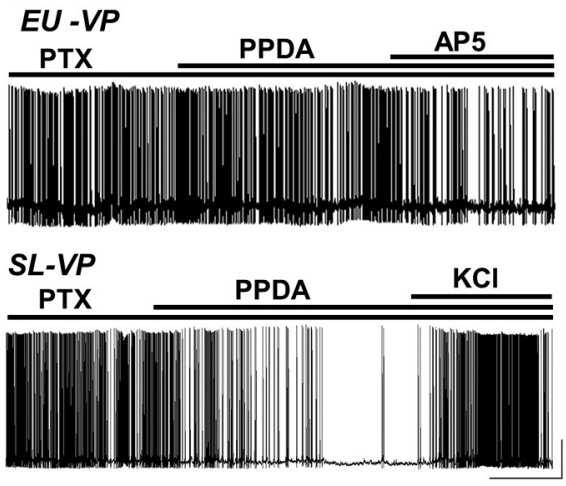

$1 \mathrm{~min}$

Figure 8. $\mathrm{Mg}^{2+}$-resistant tonic $I_{\text {NMDA }}$ upregulated neuronal firing in SON MNCS. $A$, Representative traces of neuronal firing in VP and OT neurons from rats in the EU and SL groups. Blockade of $\mathrm{Mg}^{2+}$-resistant tonic $I_{\text {NMDA }}$ (PPDA, $1 \mu \mathrm{M}$ ) decreased the firing activity in SL-VP but not in EU-VP, EU-0T, and SL-OT neurons, while subsequent application of $100 \mu \mathrm{M}$ AP5 (PPDA + AP5) efficiently decreased firing activity in all groups. $\boldsymbol{B}$, Firing frequency under each condition $[* * * p<0.001$, compared with control (CTL) Wilcoxon signed-rank test; $n=11$, EU-VP; $n=13$, SL-VP; $n=7$, EU-OT; $n=9$, SL-0T]. C, Representative traces showing the effect of PPDA on the neuronal firing of EU-VP and SL-VP neurons in the presence of an ionotropic $G A B A_{A}$ receptor antagonist, picrotoxin (PTX; $200 \mu \mathrm{m})$. D, Firing frequency of VP neurons before and during the application of PPDA in the presence of PTX under the $\mathrm{EU}(n=5)$ and SL $(n=8)$ conditions; $* p=0.02$, compared with control, paired-sample $t$ test.

recruitment of NR2D-containing NMDARs in the adult brain contributes to generation of a unique, functionally relevant extrasynaptic excitatory signaling mechanism. We propose that this novel mechanism plays an important adaptive role in these neuroendocrine cells in response to sustained physiological challenges.

Cellular mechanisms generating $\mathrm{Mg}^{2+}$-resistant tonic $I_{\mathrm{NMDA}}$ in VP neurons under SL conditions

SON MNCs represent a conspicuous example of activitydependent neuronal-glial plasticity (Tweedle and Hatton, 1977, 1984; Theodosis and Poulain, 1993) that involves reversible glial retraction from and between neighboring neurons leading to increased formation on synaptic inputs on the targeted neurons. Glial retraction with reduced GLT-1 activity increases extracellular glutamate and activates eNMDARs in SON MNCs in response to osmotic challenges (Fleming et al., 2011; Joe et al., 2014). However, in the present study, the increased extracellular glutamate level evoked by exogenous glutamate or GluT blocker was not sufficient to generate or potentiate PPDA-sensitive tonic $I_{\mathrm{NMDA}}$ in the EU and SL SON MNCs. These results imply that increased ambient glutamate levels, in the context of an altered topography of the tripartite synapse and/or GluT activity itself, are not enough to generate an $\mathrm{Mg}^{2+}$-resistant $I_{\mathrm{NMDA}}$ in VP neurons under SL conditions.

Given that ambient glutamate is sufficient to activate eNMDARs (Sah et al., 1989; Herman and Jahr, 2007; Papouin et al., 2012), altered expression and/or composition of eNMDARs could generate a tonic $I_{\mathrm{NMDA}}$ in SON MNCs regardless of ambient glutamate concentrations. Indeed, the lack of change in the abundance of NMDAR subunits previously reported after $3 \mathrm{~d}$ of $\mathrm{SL}$ (Doherty and Sladek, 2011) and passive dehydration (Carreño et al., 2011) seems to be consistent with our results showing that $3 \mathrm{~d}$ of SL was not enough to induce $\mathrm{Mg}^{2+}$-resistant tonic $I_{\mathrm{NMDA}}$ in SON MNCs (Fig. 1). Similarly, our results demonstrating that $7 \mathrm{~d}$ of SL increased NR2D expression, together with previous reports of NR1 upregulation in chronic SL (7-10 d; Decavel and Curras, 1997), imply that an increased abundance of NMDARs generates $\mathrm{Mg}^{2+}$-resistant tonic $I_{\mathrm{NMDA}}$ after $7 \mathrm{~d}$ SL in VP neurons. Our results showing that pharmacological and genetic intervention of NR2D prevented $\mathrm{Mg}^{2+}$ resistant tonic $I_{\mathrm{NMDA}}$ provide further evidence that NR2D-containing receptors play an essential role in the generation of $\mathrm{Mg}^{2+}$-resistant tonic $I_{\mathrm{NMDA}}$ in VP neurons under SL conditions.

Together, our results imply that, in addition to the changes in the neuronal-glial microenvironment, SL recruits NR2D-containing NMDARs, which in turn mediate this unique extrasynaptic signaling, shown in VP neurons.

Diversity of eNMDARs mediating tonic $I_{\text {NMDA }}$

Given that SON MNCs express NR2B and NR2D subunit proteins (Doherty and Sladek, 2011) and that NR1/NR2B/ NR2D triheteromers form functional NMDARs in both synaptic (Brothwell et al., 2008) and extrasynaptic membranes (Brickley et al., 2003), it is plausible that, in addition to NR2D 
diheteromers, triheteromeric eNMDARs composed of NR1/NR2B/NR2D subunits mediate $\mathrm{Mg}^{2+}$-resistant tonic $I_{\mathrm{NMDA}}$ in VP neurons under SL conditions. However, NR1/NR2B/NR2D triheteromers are also sensitive to ifenprodil, although less so than diheteromeric NR1/NR2B receptors (Brothwell et al., 2008), so our results showing that ifenprodil failed to block $\mathrm{Mg}^{2+}$-resistant tonic $I_{\mathrm{NMDA}}$ of VP neurons under SL conditions (Fig. $2 B$ ) challenge the hypothesis that triheteromeric NR1/NR2B/NR2D receptors or diheteromeric NR2B receptors contribute to the $\mathrm{Mg}^{2+}$-resistant tonic $I_{\mathrm{NMDA}}$ of VP neurons under SL conditions. It is also noteworthy that extracellular MK-801 failed to block $\mathrm{Mg}^{2+}$-resistant tonic $I_{\mathrm{NMDA}}$ of VP neurons in SL conditions (Fig. $2 B$ ). Combined with the fact that extracellular MK-801 preferentially interacts and blocks the NMDAR currents mediated by NR2Aand NR2B-containing NMDARs compared with NR2C- or NR2D-containig receptors in nondepolarized cells (Yamakura et al., 1993; Laurie and Seeburg, 1994; Bresink et al., 1996), insensitivity of $\mathrm{Mg}^{2+}$-resistant $I_{\mathrm{NMDA}}$ to the open channel blocker, MK-801 is also in line with the fact that NR2C/ NR2D-containing receptors mediate $\mathrm{Mg}^{2+}$-resistant $I_{\mathrm{NMDA}}$ of VP neurons.

Although NR2B does not contribute to the $\mathrm{Mg}^{2+}$-resistant tonic $I_{\mathrm{NMDA}}$ of VP neurons under SL conditions, it is broadly accepted that NR2B receptors preferentially located in extrasynaptic regions (Tovar and Westbrook, 1999) contribute to tonic $I_{\mathrm{NMDA}}$ in the brain. Like previous studies (Fleming et al., 2011), we found that ifenprodil efficiently blocked tonic $I_{\mathrm{NMDA}}$ in depolarized SON MNCs (Fig. 3). While still debated, it is generally accepted that eNMDARs are composed of NR2B-containing NMDARs. Since NR2D receptors are less sensitive than NR2B receptors to $\mathrm{Mg}^{2+}$ ion channel blockade (Kuner and Schoepfer, 1996), our results imply that both NR2B- and NR2D-containing NMDARs mediate tonic $I_{\mathrm{NMDA}}$, with their relative contributions being dependent on the depolarizing state of neurons (e.g., NR2D is predominant when neurons are hyperpolarized and NR2B and NR2D are predominant when neurons are depolarized).

Cell type-specific generation of NR2D-mediated $\mathrm{Mg}^{2+}$ resistant tonic $I_{\mathrm{NMDA}}$ in SON MNCs under SL conditions SON MNCs release VP and OT hormones into the blood in response to specific physiological demands, which are tightly linked to the electrical activity of neurons (Poulain and Wakerley, 1982; Renaud and Bourque, 1991). The excitatory inputs from the OVLT to SON MNCs are target selective for VP neurons (Yang et al., 1994; Stachniak et al., 2014), implying that they may selectively modulate the excitability of VP neurons in response to a hyperosmotic challenge. However, our results showing that enhanced glutamate input, putatively including those from OVLT, did not generate or potentiate $I_{\mathrm{NMDA}}$ in SON MNCs (Figs. 4, 5) argue against this interpretation.

It has been proposed that differential NMDA receptor composition may shape the neurophysiological properties of VP and OT neurons (Al-Ghoul et al., 1997). Indeed, VP neurons
B

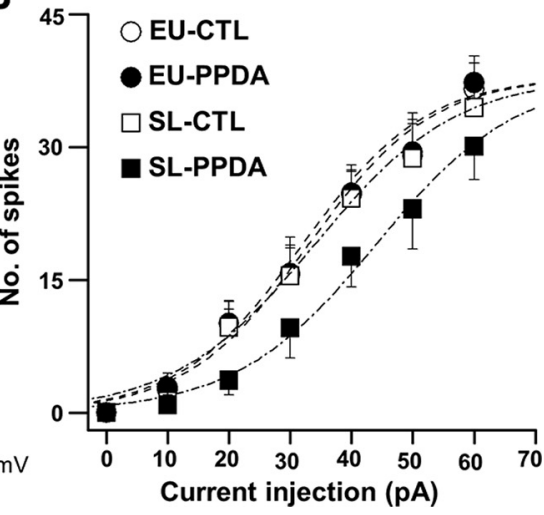

Current injection (pA)

\section{0}

$\underset{0.2 \mathrm{~s}}{+} 30$
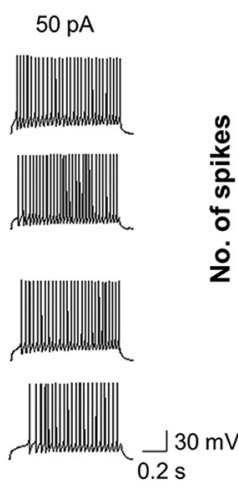

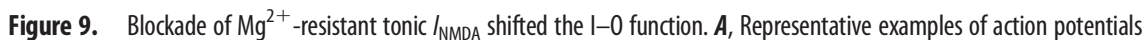

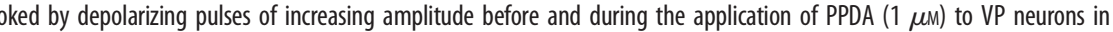
the EU and SL groups. Note the decreased numbers of spikes produced in the presence of PPDA by neurons in the SL group at each current amplitude step. $V_{\mathrm{m}}$ was held at $-58 \mathrm{mV}$ under all conditions. $\boldsymbol{B}$, Mean numbers of spikes produced as a EU (circle) and SL (square) groups. Blockade of $\mathrm{Mg}^{2+}$-resistant tonic $I_{\text {NMDA }}$ significantly shifted the I-0 relationship to the right under SL conditions (see Results) compared with control (CTL; $n=11$ in each), two-way RM ANOVA.

expressed similar levels of mRNA of the NR2D (31\%), NR2B (39\%), and NR2C (32\%) subunits, whereas the NR2B subunit is predominantly expressed (65\%) in OT neurons (Al-Ghoul et al., 1997). These findings, in addition to the results showing that NR2C/NR2D receptors exhibit weaker magnesium block and higher affinity for glycine than NR2B receptors, imply that the high NR2C/NR2D subunit could cause VP neurons to be more susceptible to glutamatergic activation than OT neurons. In this study, pharmacological and genetic intervention of NR2D receptors blocked tonic $I_{\mathrm{NMDA}}$ and suppressed the neuronal firing of VP neurons under SL conditions, which is in accordance with previous studies reporting that, at the protein level, NR2C expression is absent in the SON (Doherty and Sladek, 2011) despite the fivefold higher NR2C mRNA in VP compared with OT neurons (Al-Ghoul et al., 1997). Overall, these results imply that during a sustained osmotic challenge, NR2D-mediated tonic $I_{\text {NMDA }}$ contributes to the regulation of SON firing activity in a cell type-dependent manner. However, we cannot completely exclude the possibility that SL selectively alters the microenvironment of VP neurons rather than OT neurons, contributing to the cell type-specific nature of this effect.

\section{Functional significance of NR2D-mediated $\mathrm{Mg}^{2+}$-resistant} tonic $I_{\text {NMDA }}$ in VP neurons under SL conditions

It has long been thought that nonfunctional extrasynaptic receptors may be recruited to active synapses or functionally combined with synaptic signaling, on demand, in the brain. For example, enhanced synaptic activity functionally recruits NR2Dcontaining eNMDARs to modify excitatory postsynaptic currents in the hippocampus and cerebellum (Clark and CullCandy, 2002; Harney et al., 2008). Our results add to the known functional repertoire of eNMDARs, showing that NR2D-containing NMDARs can also be recruited in an "on-demand" basis to extrasynaptic sites to generate a functionally relevant $\mathrm{Mg}^{2+}$ resistant tonic $I_{\text {NMDA }}$ in VP neurons.

Although tonic NMDAR activation has been proposed to modulate the input-output function (Sah et al., 1989; Wu et al., 2012), such activation may also lead to cell death, possibly by an excessive $\mathrm{Ca}^{2+}$ influx (Hardingham et al., 2002). The permeability of NMDARs to $\mathrm{Ca}^{2+}$ ions may confer to NMDARs a central 
role in both synaptic plasticity under physiological conditions and neuronal death under excitotoxic pathologic conditions. In addition to other unique biophysical properties of NR2D subunit-containing NMDARs, including weak desensitization, slow deactivation, low $\mathrm{Mg}^{2+}$ sensitivity, and high glutamate affinity (Yamakura and Shimoji, 1999; Bai et al., 2013; Paoletti et al., 2013; Wyllie et al., 2013), NR2D receptors show reduced $\mathrm{Ca}^{2+}$ permeability (Siegler Retchless et al., 2012). Therefore, NR2Dcontaining eNMDARs may generate tonic $I_{\mathrm{NMDA}}$ in nondepolarized VP neurons under physiological levels of $\mathrm{Mg}^{2+}$ concentrations in the brain and contribute to upregulation of neuronal activity on an "on-demand" basis, while minimizing potential excitotoxic effects because of their lower $\mathrm{Ca}^{2+}$ permeability. However, it is noteworthy that $7 \mathrm{~d}$ SL increased serum osmolality to an equivalent level in WT and NR2D KO mice, suggesting that there is central and/or peripheral adaptation maintaining fluid homeostasis in NR2D KO mice in the SL condition. Given that increases in plasma VP induced by salt intake promotes water retention and vasoconstriction (Prager-Khoutorsky et al., 2017), future studies are warranted to further investigate the functional significance of the $\mathrm{Mg}^{2+}$-resistant tonic $I_{\mathrm{NMDA}}$ to facilitate VP release regulating sodium homeostasis, blood pressure, and kidney function in WT and NR2D KO mice.

This study shows that the recruitment of functional NR2Dcontaining NMDARs constitutes a novel mechanism by which VP neurons generate an $\mathrm{Mg}^{2+}$-resistant tonic $I_{\mathrm{NMDA}}$ and contribute to adaptive firing responses to a sustained osmotic challenge. Moreover, our results expand the general mechanisms by which neurons in the mature brain are capable of regulating a membrane potential-sensitive excitatory signaling modality in an "on-demand" manner.

\section{References}

Al-Ghoul WM, Meeker RB, Greenwood RS (1997) Differential expression of five N-methyl-D-aspartate receptor subunit mRNAs in vasopressin and oxytocin neuroendocrine cells. Brain Res Mol Brain Res 44:262-272.

Asztely F, Erdemli G, Kullmann DM (1997) Extrasynaptic glutamate spillover in the hippocampus: dependence on temperature and the role of active glutamate uptake. Neuron 18:281-293.

Bai N, Hayashi H, Aida T, Namekata K, Harada T, Mishina M, Tanaka K (2013) Dock3 interaction with a glutamate-receptor NR2D subunit protects neurons from excitotoxicity. Mol Brain 6:22.

Berretta N, Jones RS (1996) Tonic facilitation of glutamate release by presynaptic N-methyl-D-aspartate autoreceptors in the entorhinal cortex. Neuroscience 75:339-344.

Bresink I, Benke TA, Collett VJ, Seal AJ, Parsons CG, Henley JM, Collingridge GL (1996) Effects of memantine on recombinant rat NMDA receptors expressed in HEK 293 cells. Br J Pharmacol 119:195-204.

Brickley SG, Misra C, Mok MHS, Mishina M, Cull-Candy SG (2003) NR2B and NR2D subunits coassemble in cerebellar Golgi cells to form a distinct NMDA receptor subtype restricted to extrasynaptic sites. J Neurosci 23:4958-4966.

Brothwell SL, Barber JL, Monaghan DT, Jane DE, Gibb AJ, Jones S (2008) NR2B- and NR2D-containing synaptic NMDA receptors in developing rat substantia nigra pars compacta dopaminergic neurones. J Physiol 586:739-750.

Carreño FR, Walch JD, Dutta M, Nedungadi TP, Cunningham JT (2011) Brain-derived neurotrophic factor-tyrosine kinase B pathway mediates NMDA receptor NR2B subunit phosphorylation in the supraoptic nuclei following progressive dehydration. J Neuroendocrinol 23:894-905.

Chenard BL, Menniti FS (1999) Antagonists selective for NMDA receptors containing the NR2B subunit. Curr Pharm Des 5:381-404.

Ciura S, Bourque CW (2006) Transient receptor potential vanilloid 1 is required for intrinsic osmoreception in organum vasculosum lamina terminalis neurons and for normal thirst responses to systemic hyperosmolality. J Neurosci 26:9069-9075.
Clark BA, Cull-Candy SG (2002) Activity-dependent recruitment of extrasynaptic NMDA receptor activation at an AMPA receptor-only synapse. J Neurosci 22:4428-4436.

Decavel C, Curras MC (1997) Increased expression of the N-methyl-D-aspartate receptor subunit, NR1, in immunohistochemically identified magnocellular hypothalamic neurons during dehydration. Neuroscience 78:191-202.

Doherty FC, Sladek CD (2011) NMDA receptor subunit expression in the supraoptic nucleus of adult rats: dominance of NR2B and NR2D. Brain Res 1388:89-99.

Dunah AW, Yasuda RP, Wang YH, Luo J, Dávila-García M, Gbadegesin M, Vicini S, Wolfe BB (1996) Regional and ontogenic expression of the NMDA receptor subunit NR2D protein in rat brain using a subunit-specific antibody. J Neurochem 67:2335-2345.

Erreger K, Geballe MT, Kristensen A, Chen PE, Hansen KB, Lee CJ, Yuan H, Le P, Lyuboslavsky PN, Micale N, Jørgensen L, Clausen RP, Wyllie DJA, Snyder JP, Traynelis SF (2007) Subunit-specific agonist activity at NR2A-, NR2B-, NR2C-, and NR2D-containing N-methyl-D-aspartate glutamate receptors. Mol Pharmacol 72:907-920.

Feng B, Tse HW, Skifter DA, Morley R, Jane DE, Monaghan DT (2004) Structure-activity analysis of a novel NR2C/NR2D-preferring NMDA receptor antagonist: 1-(phenanthrene-2-carbonyl) piperazine-2,3-dicarboxylic acid. Br J Pharmacol 141:508-516.

Fleming TM, Scott V, Naskar K, Joe N, Brown CH, Stern JE (2011) State-dependent changes in astrocyte regulation of extrasynaptic NMDA receptor signalling in neurosecretory neurons. J Physiol 589:3929-3941.

Hansen KB, Yi F, Perszyk RE, Furukawa H, Wollmuth LP, Gibb AJ, Traynelis SF (2018) Structure, function, and allosteric modulation of NMDA receptors. J Gen Physiol 150:1081-1105.

Hanson E, Armbruster M, Lau LA, Sommer ME, Klaft ZJ, Swanger SA, Traynelis SF, Moss SJ, Noubary F, Chadchankar J, Dulla CG (2019) Tonic activation of GluN2C/GluN2D-containing NMDA receptors by ambient glutamate facilitates cortical interneuron maturation. J Neurosci 39:3611-3626.

Hardingham GE, Fukunaga Y, Bading H (2002) Extrasynaptic NMDARs oppose synaptic NMDARs by triggering CREB shut-off and cell death pathways. Nat Neurosci 5:405-414.

Harney SC, Jane DE, Anwyl R (2008) Extrasynaptic NR2D-containing NMDARs are recruited to the synapse during LTP of NMDAR-EPSCs. J Neurosci 28:11685-11694.

Herman MA, Jahr CE (2007) Extracellular glutamate concentration in hippocampal slice. J Neurosci 27:9736-9741.

Honda K, Negoro H, Dyball RE, Higuchi T, Takano S (1990) The osmoreceptor complex in the rat: evidence for interactions between the supraoptic and other diencephalic nuclei. J Physiol 431:225-241.

Huang Z, Gibb AJ (2014) Mg2 + block properties of triheteromeric GluN1GluN2B-GluN2D NMDA receptors on neonatal rat substantia nigra pars compacta dopaminergic neurones. J Physiol 592:2059-2078.

Huettner JE, Bean BP (1988) Block of N-methyl-D-aspartate-activated current by the anticonvulsant MK-801: selective binding to open channels. Proc Natl Acad Sci U S A 85:1307-1311.

Ikeda K, Araki K, Takayama C, Inoue Y, Yagi T, Aizawa S, Mishina M (1995) Reduced spontaneous activity of mice defective in the epsilon 4 subunit of the NMDA receptor channel. Brain Res Mol Brain Res 33:61-71.

Joe N, Scott V, Brown CH (2014) Glial regulation of extrasynaptic NMDA receptor-mediated excitation of supraoptic nucleus neurones during dehydration. J Neuroendocrinol 26:35-42.

Katoh A, Fujihara H, Ohbuchi T, Onaka T, Hashimoto T, Kawata M, Suzuki H, Ueta Y (2011) Highly visible expression of an oxytocin-monomeric red fluorescent protein 1 fusion gene in the hypothalamus and posterior pituitary of transgenic rats. Endocrinology 152:2768-2774.

Krupp JJ, Vissel B, Heinemann SF, Westbrook GL (1998) N-terminal domains in the NR2 subunit control desensitization of NMDA receptors. Neuron 20:317-327.

Kuner T, Schoepfer R (1996) Multiple structural elements determine subunit specificity of $\mathrm{Mg} 2+$ block in NMDA receptor channels. J Neurosci 16:3549-3558.

Laurie DJ, Seeburg PH (1994) Ligand affinities at recombinant N-methyl-Daspartate receptors depend on subunit composition. Eur J Pharmacol 268:335-345. 
Le Meur K, Galante M, Angulo MC, Audinat E (2007) Tonic activation of NMDA receptors by ambient glutamate of non-synaptic origin in the rat hippocampus. J Physiol 580:373-383.

Lee SK, Lee S, Shin SY, Ryu PD, Lee SY (2012) Single cell analysis of voltagegated potassium channels that determines neuronal types of rat hypothalamic paraventricular nucleus neurons. Neuroscience 205:49-62.

Liu Q, Wong-Riley MT (2010) Postnatal development of N-methyl-D-aspartate receptor subunits $2 \mathrm{~A}, 2 \mathrm{~B}, 2 \mathrm{C}, 2 \mathrm{D}$, and $3 \mathrm{~B}$ immunoreactivity in brain stem respiratory nuclei of the rat. Neuroscience 171:637-654.

Lozovaya NA, Grebenyuk SE, Tsintsadze TS, Feng B, Monaghan DT, Krishtal OA (2004) Extrasynaptic NR2B and NR2D subunits of NMDA receptors shape "superslow" afterburst EPSC in rat hippocampus. J Physiol 558:451-463.

Momiyama A, Feldmeyer D, Cull-Candy SG (1996) Identification of a native low-conductance NMDA channel with reduced sensitivity to $\mathrm{Mg} 2+$ in rat central neurones. J Physiol 494:479-492.

Monyer H, Burnashev N, Laurie DJ, Sakmann B, Seeburg PH (1994) Developmental and regional expression in the rat brain and functional properties of four NMDA receptors. Neuron 12:529-540.

Mullasseril P, Hansen KB, Vance KM, Ogden KK, Yuan H, Kurtkaya NL, Santangelo R, Orr AG, Le P, Vellano KM, Liotta DC, Traynelis SF (2010) A subunit-selective potentiator of NR2C- and NR2D-containing NMDA receptors. Nat Commun 1:90.

Pandit S, Jo JY, Lee SU, Lee YJ, Lee SY, Ryu PD, Lee JU, Kim HW, Jeon BH, Park JB (2015) Enhanced astroglial GABA uptake attenuates tonic GABAA inhibition of the presympathetic hypothalamic paraventricular nucleus neurons in heart failure. J Neurophysiol 114:914-926.

Paoletti P, Bellone C, Zhou Q (2013) NMDA receptor subunit diversity: impact on receptor properties, synaptic plasticity and disease. Nat Rev Neurosci 14:383-400.

Papouin T, Oliet SH (2014) Organization, control and function of extrasynaptic NMDA receptors. Philos Trans $\mathrm{R}$ Soc Lond B Biol Sci 369:20130601.

Papouin T, Ladépêche L, Ruel J, Sacchi S, Labasque M, Hanini M, Groc L, Pollegioni L, Mothet JP, Oliet SH (2012) Synaptic and extrasynaptic NMDA receptors are gated by different endogenous coagonists. Cell 150:633-646.

Park JB, Skalska S, Stern JE (2006) Characterization of a novel tonic gammaaminobutyric acidA receptor-mediated inhibition in magnocellular neurosecretory neurons and its modulation by glia. Endocrinology 147:3746-3760.

Park JB, Skalska S, Son S, Stern JE (2007) Dual GABAA receptor-mediated inhibition in rat presympathetic paraventricular nucleus neurons. J Physiol 582:539-551.

Poulain DA, Wakerley JB (1982) Electrophysiology of hypothalamic magnocellular neurones secreting oxytocin and vasopressin. Neuroscience 7:773-808.

Prager-Khoutorsky M, Choe KY, Levi DI, Bourque CW (2017) Role of vasopressin in rat models of salt-dependent hypertension. Curr Hypertens Rep 19:42.

Renaud LP, Bourque CW (1991) Neurophysiology and neuropharmacology of hypothalamic magnocellular neurons secreting vasopressin and oxytocin. Prog Neurobiol 36:131-169.

Sah P, Hestrin S, Nicoll RA (1989) Tonic activation of NMDA receptors by ambient glutamate enhances excitability of neurons. Science 246:815818.

Sayer RJ, Hubbard JI, Sirett NE (1984) Rat organum vasculosum laminae terminalis in vitro: responses to transmitters. Am J Physiol 247:R374-R379.

Shimamoto K, Lebrun B, Yasuda-Kamatani Y, Sakaitani M, Shigeri Y, Yumoto N, Nakajima T (1998) DL-threo-beta-benzyloxyaspartate, a potent blocker of excitatory amino acid transporters. Mol Pharmacol 53:195-201.

Siegler Retchless B, Gao W, Johnson JW (2012) A single GluN2 subunit residue controls NMDA receptor channel properties via intersubunit interaction. Nat Neurosci 15:406-413, S1-S2.
Stachniak TJ, Trudel E, Bourque CW (2014) Cell-specific retrograde signals mediate antiparallel effects of angiotensin II on osmoreceptor afferents to vasopressin and oxytocin neurons. Cell Rep 8:355-362.

Sun W, Wong JM, Gray JA, Carter BC (2018) Incomplete block of NMDA receptors by intracellular MK-801. Neuropharmacology 143:122-129.

Swanson LW, Sawchenko PE (1983) Hypothalamic integration: organization of the paraventricular and supraoptic nuclei. Annu Rev Neurosci 6:269324.

Theodosis DT, Poulain DA (1993) Activity-dependent neuronal-glial and synaptic plasticity in the adult mammalian hypothalamus. Neuroscience 57:501-535.

Tovar KR, Westbrook GL (1999) The incorporation of NMDA receptors with a distinct subunit composition at nascent hippocampal synapses in vitro. J Neurosci 19:4180-4188.

Traynelis SF, Wollmuth LP, McBain CJ, Menniti FS, Vance KM, Ogden KK, Hansen KB, Yuan H, Myers SJ, Dingledine R (2010) Glutamate receptor ion channels: structure, regulation, and function. Pharmacol Rev 62:405496.

Tweedle CD, Hatton GI (1977) Ultrastructural changes in rat hypothalamic neurosecretory cells and their associated glia during minimal dehydration and rehydration. Cell Tissue Res 181:59-72.

Tweedle CD, Hatton GI (1984) Synapse formation and disappearance in adult rat supraoptic nucleus during different hydration states. Brain Res 309:373-376.

Ueta Y, Fujihara H, Serino R, Dayanithi G, Ozawa H, Matsuda K, Kawata M, Yamada J, Ueno S, Fukuda A, Murphy D (2005) Transgenic expression of enhanced green fluorescent protein enables direct visualization for physiological studies of vasopressin neurons and isolated nerve terminals of the rat. Endocrinology 146:406-413.

Vicini S, Wang JF, Li JH, Zhu WJ, Wang YH, Luo JAH, Wolfe BB, Grayson DR (1998) Functional and pharmacological differences between recombinant N-methyl-D-aspartate receptors. J Neurophysiol 79:555-566.

Villarroel A, Regalado MP, Lerma J (1998) Glycine-independent NMDA receptor desensitization: localization of structural determinants. Neuron 20:329-339.

Watanabe M, Inoue Y, Sakimura K, Mishina M (1992) Developmental changes in distribution of NMDA receptor channel subunit mRNAs. Neuroreport 3:1138-1140.

Wenzel A, Villa M, Mohler H, Benke D (1996) Developmental and regional expression of NMDA receptor subtypes containing the NR2D subunit in rat brain. J Neurochem 66:1240-1248.

Wu YN, Johnson SW (2015) Memantine selectively blocks extrasynaptic NMDA receptors in rat substantia nigra dopamine neurons. Brain Res 1603:1-7.

Wu YW, Grebenyuk S, McHugh TJ, Rusakov DA, Semyanov A (2012) Backpropagating action potentials enable detection of extrasynaptic glutamate by NMDA receptors. Cell Rep 1:495-505.

Wyllie DJA, Behe P, Colquhoun D (1998) Single-channel activations and concentration jumps: comparison of recombinant NR1a/NR2A and NR1a/NR2D NMDA receptors (vol 510, pg 1, 1998). J Physiol 510:1-18.

Wyllie DJA, Livesey MR, Hardingham GE (2013) Influence of GluN2 subunit identity on NMDA receptor function. Neuropharmacology 74:4-17.

Xia P, Chen HS, Zhang D, Lipton SA (2010) Memantine preferentially blocks extrasynaptic over synaptic NMDA receptor currents in hippocampal autapses. J Neurosci 30:11246-11250.

Yamakura T, Shimoji K (1999) Subunit- and site-specific pharmacology of the NMDA receptor channel. Prog Neurobiol 59:279-298.

Yamakura T, Mori H, Masaki H, Shimoji K, Mishina M (1993) Different sensitivities of NMDA receptor channel subtypes to non-competitive antagonists. Neuroreport 4:687-690.

Yang CR, Senatorov VV, Renaud LP (1994) Organum vasculosum lamina terminalis-evoked postsynaptic responses in rat supraoptic neurones in vitro. J Physiol 477:59-74.

Yokoyama T, Saito T, Ohbuchi T, Hashimoto H, Suzuki H, Otsubo H, Fujihara H, Nagatomo T, Ueta Y (2010) TRPV1 gene deficiency attenuates miniature EPSC potentiation induced by mannitol and angiotensin II in supraoptic magnocellular neurons. J Neurosci 30:876-884. 